\title{
Investment in Schooling and the Marriage Market
}

Pierre-Andre Chiappori, Murat Iyigun, and Yoram Weiss

CID Working Paper No. 156

January 2008

(C) Copyright 2008 Pierre-Andre Chiappori, Murat Iyigun, Yoram Weiss, and the President and Fellows of Harvard College

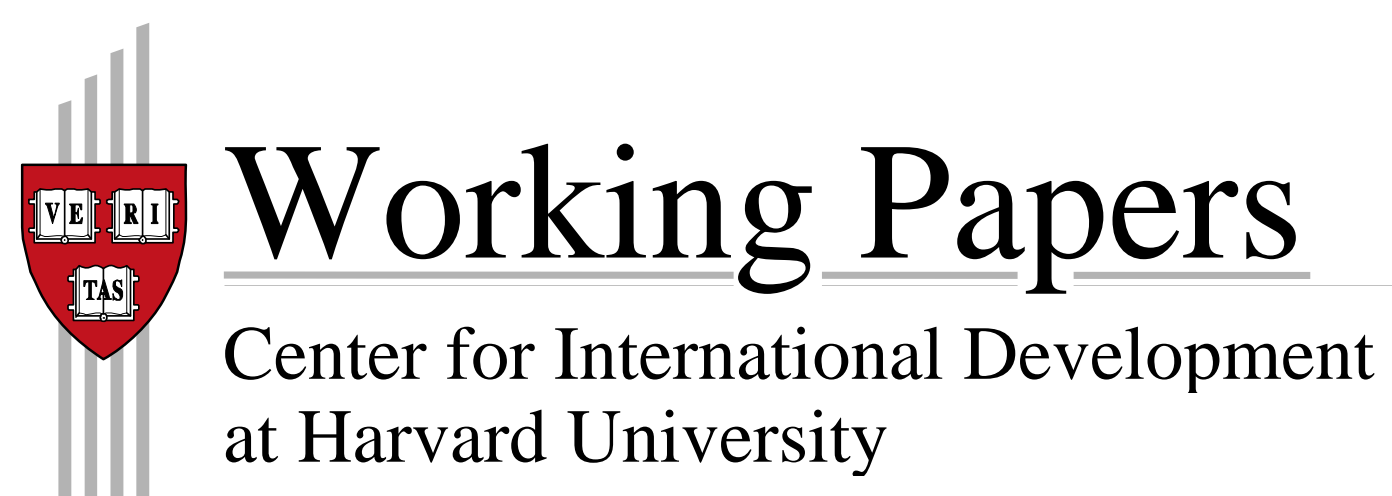




\title{
Investment in Schooling and the Marriage Market
}

\author{
Pierre-Andre Chiappori, Murat Iyigun, and Yoram Weiss
}

\begin{abstract}
We present a model with pre-marital schooling investment, endogenous marital matching and spousal specialization in homework and market production. Investment in schooling raises wages and generates two kinds of returns in our framework: a labor-market return and a marriage-market return because education can affect the intra-marital share of the surplus one can extract from marriage. We consider a household production function in which the schooling of spouses are complements, yielding positive assortative matching. If men and women have different market returns or household roles, they may have different incentives to acquire schooling, yielding a mixed equilibrium where some educated individuals marry uneducated spouses and those who educate less extract a relatively larger share of the marital surplus. The existence of large and frictionless marriage markets creates competition among potential spouses, precludes bargaining and generates premarital investments that are efficient. By combining the observations that the gender earning gap declines with schooling and that women's household time obligations have declined over time, our model provides an explanation for why women now attain higher schooling levels than men.
\end{abstract}

Keywords: The Gender Education Gap, Marriage, Labor Supply

JEL codes: C78, D61, D70 


\title{
Investment in Schooling and the Marriage Market*
}

\author{
Pierre-Andre Chiappori ${ }^{\dagger}$ Murat Iyigun ${ }^{\ddagger}$ and Yoram Weiss $^{\S}$
}

October 2007

\begin{abstract}
We present a model with pre-marital schooling investment, endogenous marital matching and spousal specialization in homework and market production. Investment in schooling raises wages and generates two kinds of returns in our framework: a labor-market return and a marriage-market return because education can affect the intra-marital share of the surplus one can extract from marriage. We consider a household production function in which the schooling of spouses are complements, yielding positive assortative matching. If men and women have different market returns or household roles, they may have different incentives to acquire schooling, yielding a mixed equilibrium where some educated individuals marry uneducated spouses and those who educate less extract a relatively larger share of the marital surplus. The existence of large and frictionless marriage markets creates competition among potential spouses, precludes bargaining and generates premarital investments that are efficient. By combining the observations that the gender earning gap declines with schooling and that women's household time obligations have declined over time, our model provides an explanation for why women now attain higher schooling levels than men.
\end{abstract}

\section{Introduction}

The purpose of this paper is to provide a simple equilibrium framework for the joint determination of pre-marital schooling and marriage patterns of men and women.

*Ellana Melnik and Linor Kiknadze provided valuable research assistance. We have benefited from various comments at the 2006 SOLE, SED, DEGIT conferences as well as seminars at Columbia University, New York University, Sabanci University, Tel Aviv University, University College London, and the University of Colorado.

${ }^{\dagger}$ Columbia University.

$\ddagger$ University of Colorado, $C I D$ at Harvard University and IZA.

$\S$ Tel Aviv University and IZA. 
Couples sort according to education and, therefore, changes in the aggregate supply of educated individuals affects who marries whom and the division of the gains from marriage. Since, unlike other attributes such as race and ethnic background, schooling is an acquired trait, the equilibrium split of marital surplus influences educational choices. Acquiring education yields two different returns: first, a higher earning capacity and better job opportunities in the labor market; second, an improvement in the intra-marital share of the surplus one can extract in the marriage market. Educational attainment influences intra-marital spousal allocations directly (due to the fact that education raises household income) and indirectly (by raising the prospects of marriage with an educated spouse and changing the spousal roles within marriage).

The gains from schooling within marriage strongly depend on the decisions of others to acquire schooling. However, since much of schooling happens before marriage, partners cannot coordinate their investments. Rather, men and women make their choices separately, based on the anticipation of marrying a "suitable" spouse with whom schooling investments are expected to generate higher returns. Therefore, an equilibrium framework is required to discuss the interaction between marriage and schooling. We provide a tractable framework of analysis that allows us to consider the impacts various changes in these markets, such as an increase in returns to schooling and the rise of female participation in the labor market, for both men and women simultaneously.

The basic ingredients of our model are as follows. We consider a frictionless marriage market in which, conditional on the predetermined spousal schooling levels, the assignments are stable. That is, there are no men or women (married or single) who wish to form a new union and there are no men or women who are married but wish to be single. Assuming transferable utility between the spouses, we can then characterize the stable assignment. We further assume that men and women can be divided into two schooling classes (high and low) and the interactions between married spouses depend only on their classes. In particular, although men and women have idiosyncratic preferences for marriage and investment in schooling, they all have the same ranking over spouses of the opposite sex which depend only on their schooling. Thus, every educated man (woman) and every uneducated man (woman) has a perfect substitute. The absence of rents allows us to pin down the shares of the marital surplus of men and women in each schooling class based on competition alone, without resorting to bargaining. These shares, together with the known returns as singles, are sufficient to determine the investments in schooling of men and women.

We apply our framework to analyze why women may overtake men in schooling despite their lower market wage rate and higher amount of housework compared 
with men; in particular, we analyze the weak response by men to increased labormarket returns to schooling. Our explanation relies on the interaction between two phenomena. First, we suggest that the increase in the levels of schooling investment by women to and above the levels of men is in part a consequence of the higher market return that women receive for schooling. The essence of the argument is that education can serve as a means to escape discrimination. In the past, however, this higher market return was washed out by the lower returns from schooling that women received within marriage. The second factor that contributes to women's education overtaking men is that as women participate more in the labor market and work less at home, their returns to schooling within marriage is drastically modified. In our model, if women become more educated than men, some of them have to marry down to match with uneducated men. Due to spousal competition in the marriage markets, this raises the share of marital surplus received by uneducated men in all marriages; conversely, uneducated women who can only marry uneducated men may suffer a reduction in their marital surplus. At equilibrium, thus, men's returns from schooling within marriage declines (or does not rise much) while women's returns rises beyond the market return. In this manner, marriage market considerations can explain the divergent patterns of educational attainments of both women and men. If we further consider changes in specialization patterns within the household, men are increasingly less likely to be the bread-winners when married to educated women and their incentive to invest in schooling declines.

We should emphasize that there are other possible reasons for why women may invest in schooling more than men. One is that there are more women than men in the marriage market at the relatively young ages at which schooling is chosen, because women marry younger. Iyigun and Walsh (2007) have shown, in a related framework, that in such a case women will be induced to invest more than men in competition for the scarce males. Another reason is that divorce is usually more harmful to women, due to the higher income of men and the usual custody arrangements (see Chiappori and Weiss, 2007). In such a case, women may use schooling as an insurance device that mitigates their costs from unwanted divorce. Gosling (2003) argues that wages are determined by several factors and women who typically lack "brawn" have stronger incentive to invest in "brains". Charles and Luoh (2003) bring evidence that among men the variability in earnings rises with schooling more than among women suggesting that investment in schooling is less "risky" for women. Finally, Goldin et al. (2006) argue that the costs of college education are lower for women because they have accumulated more education in high school.

Our work relates to several burgeoning strands in the literature: the first one is 
the theoretical work on coordination in large markets and the connections between premarital investment and intra-household allocations. (Baker and Jacobsen, 2007, Cole et al., 2001, Hadfield, 1999, Iyigun and Walsh, 2007, Lommerud and Vagstad, 2000 and Peters and Siow, 2002); the second one involves empirical work on the relationship between sex ratios and intra-household resource allocations (Angrist, 2002, Chiappori, Fortin and LaCroix, 2002, Grossbard-Shechtman, 1995, and Seitz, 2005); and the final strand uses stable matching to characterize partnership/marriage formation (Del Boca and Flinn, 2006, Ariely, Hitsch, and Hortacsu, 2006, Choo and Siow, 2006, and Choo et al., 2007).

\section{The Basic Model}

We begin with a benchmark model in which men and women are completely symmetric in their preferences and opportunities. However, by investing in schooling, agents can influence their marriage prospects and labor market opportunities. Competition over mates determines the assignment (i.e., who marries whom) and the shares in the marital surplus of men and women with different levels of schooling, depending on the aggregate number of women and men that acquire schooling. In turn, these shares together with the known market wages guide the individual decisions to invest in schooling and to marry. We investigate the rational-expectations equilibrium that arises under such circumstances.

\subsection{Definitions}

When man $i$ and woman $j$ form a union, they generate some aggregate material output $\zeta_{i j}$ that they can divide between them and the utility of each partner is linear in the share he $\backslash$ she receives (transferable utility). Man $i$ alone can produce $\zeta_{i 0}$ and woman $j$ alone can produce $\zeta_{0 j}$. The material surplus of the marriage is defined as

$$
z_{i j}=\zeta_{i j}-\zeta_{i 0}-\zeta_{0 j}
$$

In addition, there are emotional gains from marriage and the total marital surplus generated by a marriage of man $i$ and woman $j$ is

$$
s_{i j}=z_{i j}+\theta_{i}+\theta_{j}
$$

where $\theta_{i}$ and $\theta_{j}$ represent the non-economic gains of man $i$ and woman $j$ from their marriage. 


\subsection{Assumptions}

There are two equally large populations of men and women to be matched. Individuals live for two periods. Each person can choose whether to acquire schooling or not and whether and whom to marry. Investment takes place in the first period of life and marriage in the second period. Investment in schooling is lumpy and takes one period so that a person who invests in schooling works only in the second period, while a person who does not invest works in both periods. To simplify, we assume no credit markets. ${ }^{1}$ All individuals with the same schooling and of the same gender earn the same wage rate but wages may differ by gender. We denote the wage of educated men by $w_{2}^{m}$ and the wage of uneducated men by $w_{1}^{m}$, where $w_{2}^{m}>w_{1}^{m}$. The wages of educated women and uneducated women are respectively denoted by $w_{2}^{w}$ and $w_{1}^{w}$, where $w_{2}^{w}>w_{1}^{w}$. Market wages are taken as exogenous and we do not attempt to analyze here the feedbacks from the marriage market and investments in schooling to the labor market. ${ }^{2}$ We shall discuss, however, different wage structures.

We denote a particular man by $i$ and a particular woman by $j$. We represent the schooling level (class) of man $i$ by $I(i)$ where $I(i)=1$ if $i$ is uneducated and $I(i)=2$ if he is educated. Similarly, we denote the class of woman $j$ by $J(j)$ where $J(j)=1$ if $j$ is uneducated and $J(j)=2$ if she is educated. An important simplifying assumption is that the material surplus generated by a marriage of man $i$ and woman $j$ depends only on the class to which they belong. That is,

$$
s_{i j}=z_{I(i) J(j)}+\theta_{i}+\theta_{j} .
$$

We assume that the schooling levels of married partners complement each other so that

$$
z_{11}+z_{22}>z_{12}+z_{21}
$$

and that the surplus rises with the schooling of both partners. ${ }^{3}$

The per-period material utilities of man $i$ and woman $j$ as singles also depend on their class, that is $\zeta_{i 0}=\zeta_{I(i) 0}$ and $\zeta_{0 j}=\zeta_{0 J(j)}$ and are assumed to increase in $I(i)$ and $J(j)$. Thus, a more educated person has a higher utility as a single. Men and

\footnotetext{
${ }^{1}$ Allowing borrowing and lending raises issues such as whether or not one can borrow based on the income of the future spouse and enter marriage in debt (see Browning et al., in progress, Ch. 7).

2 Theoretically, wages are completely pinned down by a linear, constant returns to scale, technology. We thus ignore the impact of changes in supply on the returns from schooling. In the context of a period dominated by increasing demand to skills this omission is not as serious as it would otherwise be (see Katz and Autor, 1999).

${ }^{3}$ Complementarity between spousal traits is not necessary for our main conclusions. The key insight is that short supply in the marriage markets raises the intra-marital returns. A case in which spousal traits are substitutes is analyzed in Iyigun and Walsh (2007).
} 
women who acquire no schooling and never marry have life time utilities of $2 \zeta_{10}$ and $2 \zeta_{01}$, respectively. A person that invests in schooling must give up the first-period utility and, if he $\backslash$ she remains single, the life time utilities are $\zeta_{20}$ for men and $\zeta_{02}$ for women. Thus, the (absolute) return from schooling for never married men and women are $R^{m}=\zeta_{20}-2 \zeta_{10}$ and $R^{w}=\zeta_{02}-2 \zeta_{01}$, respectively. Note that $R^{m}$ and $R^{w}$ may (and in general will) be different.

The return to schooling of never married individuals depends only on their own market wages and we shall refer to it as the labor-market return. Those who marry have an additional return from schooling investment in the form of an increased share in the material surplus, which we shall refer to as the marriage-market return to schooling. Finally, investment in schooling is associated with idiosyncratic costs (benefits) denoted by $\mu_{i}$ for men and $\mu_{j}$ for women.

The idiosyncratic preference parameters are assumed to be independent of each other and across individuals. We denote the distributions of $\theta$ by $F(\theta)$ and assume that this distribution is symmetric around its zero mean. Also, we let $G(\mu)$ denote the distribution of $\mu$.

\subsection{The Marriage Market}

Any stable assignment of men to women must maximize the aggregate marital surplus over all possible assignments (Shapley and Shubik, 1972). The maximization of the aggregate surplus is equivalent to the maximization of aggregate output because the utilities as singles are independent of the assignment. The dual of this linear programming problem implies the existence of non-negative shadow prices associated with the constraints of the primal that each person can be either single or married to one spouse. We denote the shadow price of woman $j$ by $u_{j}$ and the shadow price of man $i$ by $v_{i}$. The complementarity slackness conditions require that

$$
z_{I(i) J(j)}+\theta_{i}+\theta_{j} \leq v_{i}+u_{j}
$$

with equality if $i$ and $j$ are married and inequality otherwise.

The complementarity slackness conditions are equivalent to

$$
\begin{aligned}
v_{i} & =\operatorname{Max}\left\{\operatorname{Max}_{j}\left[z_{I(i) J(j)}+\theta_{i}+\theta_{j}-u_{j}\right], 0\right\} \\
u_{j} & =\operatorname{Max}\left\{\operatorname{Max}_{i}\left[z_{I(i) J(j)}+\theta_{i}+\theta_{j}-v_{i}\right], 0\right\},
\end{aligned}
$$

which means that the assignment problem can be decentralized. That is, given the shadow prices $u_{j}$ and $v_{i}$, each agent marries a spouse that yields him $\backslash$ her the highest 
share in the marital surplus. We can then define $\bar{u}_{j}=u_{j}+\zeta_{0 j}$ and $\bar{v}_{i}=v_{i}+\zeta_{i 0}$ as the reservation utility levels that woman $j$ and man $i$ require to participate in any marriage. In equilibrium, a stable assignment is attained and each married person receives his $\backslash$ her reservation utility, while each single man receives $\zeta_{i 0}$ and each single woman receives $\zeta_{0 j}$.

Our specification imposes a restrictive but convenient structure in which the interactions between agents depend on their group affiliation only, i.e., their levels of schooling. Assuming that, in equilibrium, at least one person in each class marries, the endogenously-determined shadow prices of man $i$ in $I(i)$ and married $j$ in $J(j)$ can be written in the form,

$$
v_{i}=\operatorname{Max}\left(V_{I(i)}+\theta_{i}, 0\right) \quad \text { and } \quad u_{j}=\operatorname{Max}\left(U_{J(j)}+\theta_{j}, 0\right)
$$

where

$$
V_{I}=\operatorname{Max}_{J}\left[z_{I J}-U_{J}\right] \quad \text { and } \quad U_{J}=\underset{I}{\operatorname{Max}}\left[z_{I J}-V_{I}\right]
$$

are the shares that the partners receive from the material surplus of the marriage (not accounting for the idiosyncratic effects $\theta_{i}$ and $\theta_{j}$ ). All agents of a given type receive the same share of the material surplus $z_{I J}$ no matter whom they marry, because all the agents on the other side rank them in the same manner. Any man (woman) of a given type who asks for a higher share than the "going rate" cannot obtain it because he (she) can be replaced by an equivalent alternative. It is important to note that $V_{I}$ (and $U_{J}$ ) can be negative. In that case, the material utility that agent $i \in I$ receives when married is less than what he would get as single. He may nevertheless choose to marry if the non-monetary gain he derives from marriage, $\theta_{i}$, compensates for his material loss.

Although we assume equal numbers of men and women in total, it is possible that the equilibrium numbers of educated men and women will differ. We shall assume throughout that there are some uneducated men who marry uneducated women and some educated men who marry educated women. This means that the equilibrium shares must satisfy

$$
\begin{aligned}
& U_{2}+V_{2}=z_{22}, \\
& U_{1}+V_{1}=z_{11} .
\end{aligned}
$$

In addition, stability requires that

$$
\begin{aligned}
& U_{1}+V_{2} \geq z_{21}, \\
& U_{2}+V_{1} \geq z_{12} .
\end{aligned}
$$


It is impossible that both conditions above hold as equalities because this would imply

$$
z_{22}+z_{11}=z_{12}+z_{21}
$$

which violates assumption (4) that the education levels of the spouses are complements. Thus, either educated men marry uneducated women or educated women marry uneducated men but not both.

The previous equations imply that, at any stable match, we have

$$
z_{21}-z_{11} \leq V_{2}-V_{1} \leq z_{22}-z_{12}
$$

and

$$
z_{12}-z_{11} \leq U_{2}-U_{1} \leq z_{22}-z_{21} .
$$

One may interpret the differences $U_{2}-U_{1}$ and $V_{2}-V_{1}$ as the return to schooling in marriage for women and men, respectively. The quantity $z_{22}-z_{21}$, which reflects the contribution of an educated woman to the material surplus of a marriage with an educated man, provides an upper bound on the return that a woman can obtain through marriage, while her contribution to a marriage with an uneducated man, $z_{12}-z_{11}$, provides a lower bound; analogous bounds apply to men.

We can then classify the possible matching patterns as follows: Under strict positive assortative mating, educated men marry only educated women and uneducated men marry only uneducated women, and equations (11) and (12) will hold as inequalities. If there are more educated men than women among the married, some educated men will marry uneducated women and condition (11) also will hold as equality. Then conditions (9) through (11) imply

$$
\begin{aligned}
& U_{2}-U_{1}=z_{22}-z_{21}, \\
& V_{2}-V_{1}=z_{21}-z_{11} .
\end{aligned}
$$

If there are more educated women than men among the married, equation (12) will hold as equality; then conditions (9), (10) and (12) imply

$$
\begin{gathered}
V_{2}-V_{1}=z_{22}-z_{12}, \\
U_{2}-U_{1}=z_{12}-z_{11} .
\end{gathered}
$$

When types mix in the marriage market equilibrium, we see that the side that is in short supply receives the marginal contribution to a marriage with an educated 
spouse, while the side in excess supply receives the marginal contribution to a marriage with an uneducated spouse.

It should be noted that the material surplus shares $V_{I}$ and $U_{J}$ can be negative. Although no man or woman marries if the marital surplus, $V_{I(i)}+\theta_{i}$ or $U_{J(i)}+\theta_{i}$ is negative, it is possible that the marginal person in a class is willing to give up in marriage some of the material output that he $\backslash$ she has as single, provided that the nonmonetary benefit from marriage is sufficiently large. Then, all men (women) in that class are also willing to do so and the common factors, $V_{I}$ or $U_{J}$ become negative. However, stability implies that the returns to schooling in marriage, $V_{2}-V_{1}$ and $U_{2}-U_{1}$, which are our main concern, cannot be negative.

\subsection{Investment Decisions}

We assume rational expectations so that, in equilibrium, individuals know $V_{I}$ and $U_{J}$, which are sufficient statistics for investment decisions. Given these shares and knowledge of their own idiosyncratic preferences for marriage, $\theta$, and costs of schooling, $\mu$, agents know for sure whether or not they will marry in the second period, conditional on their choice of schooling in the first period.

Man $i$ chooses to invest in schooling if

$$
\zeta_{20}-\mu_{i}+\operatorname{Max}\left(V_{2}+\theta_{i}, 0\right) \geq 2 \zeta_{10}+\operatorname{Max}\left(V_{1}+\theta_{i}, 0\right) .
$$

Similarly, woman $j$ chooses to invest in schooling if

$$
\xi_{02}-\mu_{j}+\operatorname{Max}\left(U_{2}+\theta_{j}, 0\right) \geq 2 \zeta_{01}+\operatorname{Max}\left(U_{1}+\theta_{j}, 0\right) .
$$

Figure 1 describes the choices made by different men. Men for whom $\theta<-V_{2}$ do not marry and invest in schooling if and only if $\mu \leq R^{m} \equiv \zeta_{20}-2 \zeta_{10}$. Men for whom $\theta \geq-V_{1}$ always marry and they invest in schooling if and only if $\mu \leq R^{m}+V_{2}-V_{1}$. Finally, men for whom $-V_{2} \leq \theta<-V_{1}$ marry if they acquire education and do not marry if they do not invest in schooling. These individuals acquire education if $\mu \leq R^{m}+V_{2}+\theta$. In this range, there are two motives for schooling: to raise future earning capacity and to enhance marriage. We assume that the variability in $\theta$ and $\mu$ is large enough to ensure that all these regions are non-empty in equilibrium. In particular, we assume that, irrespective of marital status, there are some men and women who prefer not to invest in schooling and some men and women who prefer to invest in schooling. ${ }^{4}$ Similarly, we assume that the support of the $\theta$ distribution is

\footnotetext{
${ }^{4}$ That is, the upper bound of the support of the $\mu$ distribution is such that $\mu_{\max }>\max \left[R^{m}+\right.$ $\left.z_{22}-z_{12}, R^{w}+z_{22}-z_{21}\right]$ while the lower bound satisfies $\mu_{\min }<\min \left[R^{m}, R^{w}\right]$.
} 
'large, so that, irrespective of the education decision, there are some individuals who wish not to marry and some who wish to marry.

Inspecting Figure 1, we see that the proportion of men who invest in schooling is

$$
G\left(R^{m}\right) F\left(-V_{2}\right)+\left[1-F\left(-V_{1}\right)\right] G\left(R^{m}+V_{2}-V_{1}\right)+\int_{-V_{2}}^{-V_{1}} G\left(R^{m}+V_{2}+\theta\right) f(\theta) d \theta
$$

the proportion of men who marry is

$$
\left[1-F\left(-V_{1}\right)\right]+\int_{-V_{2}}^{-V_{1}} G\left(R^{m}+V_{2}+\theta\right) f(\theta) d \theta,
$$

and the proportion of men who invest and marry is

$$
\left[1-F\left(-V_{1}\right)\right] G\left(R^{m}+V_{2}-V_{1}\right)+\int_{-V_{2}}^{-V_{1}} G\left(R^{m}+V_{2}+\theta\right) f(\theta) d \theta .
$$

In equation (18), the first term represents the proportion of men who don't marry and get educated; the second term denotes the proportion of men who do marry and get educated; the final term is equal to those men who get married because they are educated. Similarly, in equation (19), we have the proportion of men who

marry regardless of their educational status in the first term and those who marry due to their educational attainment in the second term. By definition, equation (20) comprises of the final two terms of equation (18).

The higher are the returns from schooling in the labor market, $R^{m}$, and in marriage, $V_{2}-V_{1}$, the higher is the proportion of men who acquire schooling. A common increase in the levels $V_{2}$ and $V_{1}$ also raises investment because it makes marriage more attractive and schooling obtains an extra return within marriage. For the same reason, an increase in the market return $R^{m}$ raises the proportion of men that marry. Analogous expressions hold for women.

\subsection{Equilibrium}

In the marriage market equilibrium, the numbers of men and women who marry must be the same. Using equation (19) and applying symmetry of $F(\theta)$, we can write this condition as

$$
F\left(V_{1}\right)+\int_{V_{1}}^{V_{2}} G\left(R^{m}+V_{2}-\theta\right) f(\theta) d \theta=F\left(U_{1}\right)+\int_{U_{1}}^{U_{2}} G\left(R^{w}+U_{2}-\theta\right) f(\theta) d \theta
$$


where the LHS of (21) represents the proportion of men who marry and the RHS denotes that of women who marry (recall that we assume equal number of men and women).

One can show that a unique equilibrium always exists (see Appendix). Depending on the parameters, it can be one of the three following types:

1. Strictly positive assortative mating: Educated men marry only educated women and uneducated men marry only uneducated women. Given that we impose condition (21), the number of educated (uneducated) men who marry must equal the number of educated (uneducated) women who marry. Using condition (20) and symmetry of $F(\theta)$, an equal number of uneducated men and uneducated women marry when

$$
F\left(V_{1}\right)\left[1-G\left(R^{m}+V_{2}-V_{1}\right)\right]=F\left(U_{1}\right)\left[1-G\left(R^{w}+U_{2}-U_{1}\right)\right] .
$$

The equilibrium, in that case, satisfies (22) in addition to (9), (10) and (21).

The other two cases involve some mixing of types. Then, equation (22) is replaced by an inequality and the shares are determined by the boundary conditions on the returns to schooling within marriage for either men or women, whichever is applicable.

Specifically:

2. Some educated men marry uneducated women. Then, there must be fewer uneducated men than uneducated women among the married

$$
F\left(V_{1}\right) G\left(-R^{m}+V_{1}-V_{2}\right)<F\left(U_{1}\right) G\left(-R^{w}+U_{1}-U_{2}\right)
$$

and women receive their maximal return from schooling in marriage while men receive their minimal return. This equilibrium satisfies (14) in addition to (9), (10) and (21).

3. Some educated women marry uneducated men. Now we have

$$
F\left(V_{1}\right) G\left(-R^{m}+V_{1}-V_{2}\right)>F\left(U_{1}\right) G\left(-R^{w}+U_{1}-U_{2}\right)
$$

and men receive their maximal return from schooling in marriage, while women receive their minimal return. This equilibrium satisfies (15) in addition to (9), (10), and (21). 
The two first cases are described in Figures 2 and 3, where we depict the equilibrium conditions in terms of $V_{1}$ and $V_{2}$ after we eliminate $U_{1}$ and $U_{2}$ using (9) and (10). The two positively-sloped and parallel lines in these figures describe the boundaries on the returns to schooling of men within marriage. The negatively-sloped line describes the combinations of $V_{1}$ and $V_{2}$ that maintain equality in the numbers of men and women who wish to marry. The steeper positively-sloped line describes the combinations of $V_{1}$ and $V_{2}$ that maintain equality in the numbers of men and women that acquire no schooling and marry. The slopes of these lines are determined by the following considerations: An increase in $V_{1}$ (and a reduction in $U_{1}$ ), keeping $V_{2}$ and $U_{2}$ constant, induces more men and fewer women to prefer marriage. An increase in $V_{2}$ holding $V_{1}$ has a similar effect. Thus, $V_{1}$ and $V_{2}$ are substitutes in terms of their impact on the incentives of men to marry and $U_{1}$ and $U_{2}$ are substitutes in terms of their impact on the incentives of women to marry. Therefore, equality in the number of men and women who wish to marry can be maintained only if $V_{2}$ declines when $V_{1}$ rises. At the same time, an increase in $V_{1}$ (and a reduction in $U_{1}$ ), keeping $V_{2}$ and $U_{2}$ constant, increases the number of men that would not invest and marry and reduces the number of women who wish to acquire no schooling and marry. Therefore, equality in the numbers of uneducated men and women who wish to marry can be maintained only if $V_{2}$ rises when $V_{1}$ rises so that the rates of return to education within marriage are restored.

As long as the model is completely symmetric, that is $R^{m}=R^{w}$ and $z_{12}=z_{21}$, the equilibrium is characterized by equal sharing: $V_{2}=U_{2}=z_{22} / 2$ and $U_{1}=V_{1}=z_{11} / 2$. With these shares, men and women have identical investment incentives. Hence, the number of educated (uneducated) men equals the number of educated (uneducated) women, both among the singles and the married. Such a solution is described by point $e$ in Figure 2, where the lines satisfying conditions (21) and (22) intersect. There is a unique symmetric equilibrium. However, with asymmetry, when either $R^{m} \neq R^{w}$ or $z_{12} \neq z_{21}$, there may be a mixed equilibrium where the line representing condition (21) intersects either the lower or upper bound on $V_{2}-V_{1}$ so that condition (22) holds as an inequality. Such a case is illustrated by the point el in Figure 3. In this equilibrium, educated men obtain the lower bound on their return to education within marriage, $z_{21}-z_{11}$. The equilibrium point $e l$ is on the lower bound and above the blue line satisfying condition (22), indicating excess supply of educated men.

An important issue in the literature is whether the equilibrium premarital investments in education are efficient. In markets with frictions or small number of traders are usually characterized by inefficient premarital investments (Lommerud and Vagstad, 2000, Baker and Jacobsen, 2007). However, in our model with many 
agents and no frictions, the marital shares that individuals expect to receive within marriage induce them to fully internalize the social gains from their premarital investments and investments are efficient (see Browning et al., 2007, Ch. 12, Cole et al., 2001, Peters and Siow, 2002 and Iyigun and Walsh, 2007).

\section{Gender Differences in the Incentive to Invest}

In this section, we first review some relevant empirical observations on marriage and spousal labor supply patterns as well as schooling by gender. Then, we utilize the model above to analyze how these empirical observations can come about and explore their resource allocation and matching implications.

\subsection{Background}

One of the salient trends in recent decades is the increased investment in education by women and the closing of the gap in schooling between men and women. In several developed countries, women now have more schooling than men. ${ }^{5}$

It is well documented that the market return to schooling has risen, especially in the second half of the 20th century. Thus, it is not surprising that women's demand for education has risen. What is puzzling, however, is the differential response of men and women to the changes in the returns to schooling. Women still receive lower wages in the labor market and spend more time at home than men, although these gaps have narrowed over time. Hence, one could think that women should invest in schooling less than men because education appears to be less useful for women both at home and in the market. In fact, while women considerably increased their investment in education in the last four decades, men hardly responded to the higher returns to schooling since the 1970s (see Goldin et al., 2006), although their market returns from schooling appears to have increased at least as much as for women.

Figure 4 describes the time trends in levels of school completion for men and women, aged 30 to 40, in the United States. As seen, the proportions of women with some college education, college completion and advanced degrees (M.A., Ph.D.) have increased much faster than the corresponding proportions for men. By 2003, women had overtaken men in all of these three categories.

As seen in Figure 5, couples sort positively according to schooling and for about 50 percent of the married couples, the husband and wife have the same level of schooling

\footnotetext{
${ }^{5}$ Goldin et al. (2006) show that starting with the 1970 birth cohort; women have attained higher college graduation rates than men in the United States. They find similar reversal in 15 OECD countries.
} 
(when broadly classified into 5 groups). However, the changes in the aggregate number of educated men and women had a marked influence on who marries whom; 30 percent of the couples in the earlier cohorts had husbands who were more educated, whereas 30 percent of the couples in recent cohorts had wives with higher levels of educational attainment.

Figure 6 brings evidence on work patterns within couples for husbands and wives (aged 30-40), by the level of schooling (college or more and less than college) of the two spouses, for the periods 1976-80 and 2001-2005. We see that in the early period, 197680,56 percent of the couples in which the wife is more educated than her husband followed the "traditional" division of labor whereby the husband worked full time in the market while the wife did not work at all or worked part time. In the later period, 2001-2005, this pattern is reversed with 37 percent of such couples following the traditional household roles. This switch indicates a shift from a traditional division of labor to an efficient one. The trend of increased labor force participation of married women is observed (to a lesser degree) among the other types of couples, including those in which the husband is more educated than the wife and those in which the spouses have the same level of education. However, the overall increase in female participation is further enhanced by the rise in the proportion of couples in which the wife is more educated than the husband (as displayed in Figure 5) and, between spouses, by changes in the division of labor (as displayed in Figure 6).

Table 1 brings evidence on time allocation of married men and women (aged 2059) in the United States who have young children for the years 1975 and 2003. It is seen that women spend a substantially larger amount of time than men in non-market work. However, over time, the gap declined as women have increased their market work and reduced their non-market work, while men have reduced their market work and increased their non-market work. In 1975, married women with children 1-5 years old spent about 80 percent of their total working hours on non-market work, while this percentage for men was only 20 percent. By 2003, married women with young children had reduced their share of non-market work to 68 percent while married men had increased it to 32 percent. In 2003, the total amount of work performed by married men and women with children is quite similar, 9.35 and 8.72 hours per day, respectively.

Among the possible reasons for the changes in investment patterns of men and women are the changes in their market return from schooling and the household work that they perform. Figure 7 presents the time trends in the hourly wage differentials and hours worked by schooling for men and women in the United States. ${ }^{6}$ As seen,

\footnotetext{
${ }^{6}$ These figures are for salaried whites workers aged 25-54. Hourly wage observations of less than
} 
in Figure 7.a, women receive a higher increase in wages than men when they acquire college or advanced degrees. Even when we aggregate college and advanced degrees, this female advantage remains (Figure 7.b). ${ }^{7}$ To the extent that hours of work are determined exogenously, women may receive a return for their education also in the form of increased hours of work. Figure 7.c presents the impact of college or advanced degree (compared with a high school degree) on the annual hours worked by men and women. Using Tobit regressions (controlling for (potential) years of experience, region dummies, children and marital status), we see that the proportional impact of schooling is larger for women. Most men work and they raise their labor supply by about 10 percentage points when schooling is raised from high school to college or more. For women the expected number of hours (including none) rises with schooling by about 20 percentage points. However, the expected number of hours conditional on employment is smaller, indicating that the larger impact of schooling on hours among women is mainly a consequence of increased participation in the labor force. We conclude from Figures 7.a to 7.c that the returns to schooling for women in terms of wages and hours are larger for women than for men, but this advantage has been declining over the period 1976-2005 as women were becoming more similar to men in terms of labor force participation.

\subsection{Model Implications}

Now we discuss differences between women and men that can cause them to invest at different levels according to our model. We discuss two possible sources of asymmetry: (1) In the labor market, women may receive lower wages than men; this would lower the schooling return for working women. (2) In marriage, women may be required to take care of the children; this would lower the schooling return for married women. Either of these can induce women to invest less in schooling. And, according to the framework we advanced above, the lower incentives of women to invest can create equilibria with mixing, where educated men are in excess supply and some of them marry less-educated women.

To illustrate these effects we shall perform several comparative statics exercises, starting from a benchmark equilibrium with strictly positive assortative matching, resulting from a complete equality between the sexes in wages and household roles.

2 dollars or more than 200 dollars are considered as missing. The reported coefficients are for the school level dummies in a Mincerian wage equation which is quadratic in (potential) years of experience and includes region dummies. We apply a Heckman correction to adjust for selectivity using children and marital status, as identifying variables.

${ }^{7}$ Similar results are reported by Gosling (2003) for Britain and Dougherty (2005) for the United States using the NLS data. 


\subsubsection{The Household}

We use a rudimentary structural model to trace the impact of different wages and household roles of men and women on marital output and surplus. We assume that, irrespective of the differences in wages or household roles, men and women have the same preferences given by

$$
u=c q+\theta
$$

where $c$ is a private good, $q$ is a public good that can be shared if two people marry but is private if they remain single, and $\theta$ is the emotional gain from being married (relative to remaining single). The household public good is produced according to a household production function

$$
q=e+\gamma t
$$

where $e$ denotes purchased market goods, $t$ is time spent working at home and $\gamma$ is an efficiency parameter that is assumed to be independent of schooling. ${ }^{8}$

This specification implies transferable utility between spouses and allows us to trace the impact of different market wages or household roles on the decisions to invest and marry. Time worked at home is particularly important for parents with children. To simplify, we assume that all married couples have one child and that rearing it requires a specified amount of time $t=\tau$, where $\tau$ is a constant such that $0 \leq \tau<1$. Initially, we shall assume that, due to social norms, all the time provided at home is supplied by the mother. Also, individuals who never marry have no children and for them we set $\tau=0$.

If man $i$ of class $I$ with wage $w_{I(i)}^{m}$ marries woman $j$ of class $J$ with wage $w_{J(j)}^{w}$, their joint income is $w_{I(i)}^{m}+(1-\tau) w_{J(j)}^{w}$. Any efficient allocation of the family resources maximizes the partners' sum of utilities given by $\left[w_{I(i)}^{m}+(1-\tau) w_{J(j)}^{w}-e\right](e+\tau \gamma)+\theta_{i}$ $+\theta_{j}$. In an interior solution with a positive money expenditure on the public good, the maximized material output is

$$
\zeta_{i j}=\frac{\left[w_{I(i)}^{m}+\tau \gamma+(1-\tau) w_{J(j)}^{w}\right]^{2}}{4} .
$$

Note that the wages of the husband and wife complement each other in generating marital output, which is a consequence of sharing the public good. ${ }^{9}$

\footnotetext{
${ }^{8}$ It is well known that the mother's education has strong influence on child quality (see Behrman, 1997 and Glewwe 1999, for example). However, the qualitative results will be unaffected as long as schooling has a larger effect on market wages than on productivity at home. Such an assumption is consistent with the strong positive effect of education on the number of hours worked by women (see Figure 7.c).

${ }^{9}$ The first-order condition for $e$ is

$$
\left[w_{I(i)}^{m}+(1-\tau) w_{J(j)}^{w}-e\right]-(e+\tau \gamma) \leq 0 .
$$
}


An unmarried man $i$ solves

$$
\underset{e_{i}, c_{i}}{\operatorname{Max}} c_{i} e_{i}
$$

subject to

$$
c_{i}+e_{i}=w_{I(i)}^{m},
$$

and his optimal behavior generates a utility level of $\zeta_{i 0}=\left(w_{I(i)}^{m} / 2\right)^{2}$. A single woman $j$ solves an analogous problem and obtains $\zeta_{0 j}=\left(w_{J(j)}^{w} / 2\right)^{2}$. Therefore, the total marital surplus generated by the marriage in the second period is

$$
z_{i j}=\frac{\left[w_{I(i)}^{m}+\tau \gamma+(1-\tau) w_{J(j)}^{w}\right]^{2}-\left(w_{I(i)}^{m}\right)^{2}-\left(w_{J(j)}^{w}\right)^{2}}{4} .
$$

The surplus of a married couple arises from the fact that married partners jointly consume the public good. If the partners have no children and $\tau=0$, the gains arise solely from the pecuniary expenditures on the public good. In this case, the surplus function is symmetric in the wages of the two spouses. If the couple has a child, however, and the mother takes care of it, then the mother's contribution to household output is a weighted average of her market wage and productivity at home. We assume that $w_{2}^{w}>\gamma>w_{1}^{w}$ so that educated women are more productive in the market and uneducated women are more productive at home. The surplus function in (28) maintains complementarity between the wages of the husband and wife, which is a consequence of sharing the public good. However, the assumed asymmetry in household roles between men and women implies that a higher husband's wage always raises the surplus but a higher mother's wage can reduce the surplus. In other words, it may be costly for a high-wage woman to marry and have a child because she must spend time on child care, while if the woman does not marry, her utility as a single remains $w_{J(j)}^{2} / 4$. In addition, it is no longer true that $z_{21}=z_{12} \cdot{ }^{10}$

As long as one assumes that, due to social norms, all the time provided at home is supplied by the mother, all the gains from marriage arise from sharing a public good and the wages of the partners complement each other so that $z_{11}+z_{22}>z_{12}+z_{21}$.

Hence, $e=\left[w_{I(i)}^{m}+(1-\tau) w_{J(j)}^{w}-\tau \gamma\right] / 2$ in an interior solution. The maximized material output in this case is $\left[w_{I(i)}^{m}+\tau \gamma+(1-\tau) w_{J(j)}^{w}\right]^{2} / 4$. If $e=0$, the maximal material output is $\left[w_{I(i)}^{m}+(1-\tau) w_{J(j)}^{w}\right] \tau \gamma$, which would imply an additive surplus function, contradicting our assumption of complementarity. A sufficient condition for a positive $e$ is $w_{1}^{m}+(1-\tau) w_{1}^{w}>\tau \gamma$ if the wife works at home and $w_{1}^{w}+(1-\tau) w_{1}^{m}>\tau \gamma$ if the husband works at home. We assume hereafter that these conditions hold.

${ }^{10}$ For instance, when the wages of men and women are equal but $\tau>0$, we have

$$
z_{21}-z_{12}=\frac{\tau\left(w_{2}-w_{1}\right)}{2}\left[(1-\tau) \frac{w_{2}+w_{1}}{2}+\tau \gamma\right]>0 .
$$


If the division of labor is determined efficiently and the partners assign the spouse with the lower wage to take care of the child, complementarity continues to hold for sufficiently low time requirements, i.e., $\tau$ close to 0 . However, for $\tau$ close to 1 , the wages of the two partners become substitutes, that is, $z_{11}+z_{22}<z_{12}+z_{21}$, because wage differentials between spouses increase the gain from specialization (see Becker, 1991, Ch. 2). Thus, whether couples act efficiently or according to norms, influences the equilibrium patterns of assortative mating. ${ }^{11}$

\subsubsection{The Impact of the Wage Gap}

We are now ready to examine the implications of gender wage differences. The gender difference in wages can be an outcome of discrimination associated, for instance, with fewer opportunities for investment on the job. ${ }^{12}$ Such discrimination can reduce or increase the incentives of women to invest, depending on whether discrimination is stronger at the low or high levels of schooling.

Starting from a benchmark of complete equality between the sexes in wages and household roles such that $w_{1}^{m}=w_{1}^{w}=w_{1}, w_{2}^{m}=w_{2}^{w}=w_{2}$ and $\tau=0$, yielding an equilibrium with strictly positive assortative mating and equal shares (point $e$ in Figure 2 ), we examine the impact of an increase in the wage of educated men, $w_{2}^{m}$, combined with a reduction in the wage of educated women, $w_{2}^{w}$, holding the wage of uneducated men at the benchmark value, $w_{1}$. To isolate the role of market returns, assume that the increase in the wage of educated men exactly compensates the reduction in the wage of educated women so that marital output is unaffected and symmetry is maintained. In other words, the change in wages affect directly only the returns as singles, $R^{m}$ and $R^{w}$. Men's higher market return from schooling encourages their investment in schooling and also strengthens their incentives to marry, because schooling obtains an additional return within marriage. In contrast, women's lower return to schooling

\footnotetext{
${ }^{11}$ For instance, let $w_{2}^{m}>w_{2}^{w}>w_{1}^{m}$ and define

$$
\begin{aligned}
f(\tau) \equiv & 4\left(z_{11}+z_{22}-z_{12}-z_{21}\right) \\
= & {\left[w_{1}^{m}+\tau \gamma+(1-\tau) w_{1}^{w}\right]^{2}+\left[w_{2}^{m}+\tau \gamma+(1-\tau) w_{2}^{w}\right]^{2} } \\
& \left.-\left[w_{2}^{w}+\tau \gamma+(1-\tau) w_{1}^{m}\right)\right]^{2}-\left[w_{2}^{m}+\tau \gamma+(1-\tau) w_{1}^{w}\right]^{2} .
\end{aligned}
$$
}

Then, $f(\tau)>0$ if $\tau=0$ and $f(\tau)<0$ if $\tau=1$, where $\forall \tau \in[0,1], f^{\prime}(\tau)<0$.

${ }^{12}$ Discrimination here simply means that conditioned on their level of schooling, women expect lower wages and lesser work opportunities than men during their work careers. This outcome can result from a variety of causes including self-selection of women into part-time jobs with lower wages and weaker incentives for women to acquire, or for employers to provide, on the job training. 
reduces their incentives to invest and marry. These changes create excess supply of men who wish to invest and marry. Consequently, to restore equilibrium, the rates of returns that men receive within marriage must decline implying that, for any $V_{1}$, the value of $V_{2}$ that satisfies conditions (21) and (22) must decline.

For moderate changes in wages, strictly positive assortative mating continues to hold. However, the equilibrium value of $V_{2}$ declines and educated men receive a lower share of the surplus than they do with equal wages in any marriage. That is, as market returns of men rise and more men wish to acquire education, the marriage market response is to reduce the share of educated men in all marriages. When the gap between $R^{m}$ and $R^{w}$ becomes large, the equilibrium shifts to a mixed equilibrium, such that the return from schooling of men is at its lower bound an some educated men marry uneducated women (such as point $e l$ in Figure 3). Both $V_{1}$ and $V_{2}$ are lower in the new equilibrium so that all men (women), educated and uneducated, receive lower (higher) shares of the material surplus when men have stronger market incentives to invest in schooling than women.

These results regarding the shares of married men and women in the material surplus must be distinguished from the impact of the shares in the material output. If men get a higher return from schooling as singles (due to the fact that their labormarket return from schooling is higher than that of women), then their share of the material output can be higher even though they receive a lower share of the surplus. The same remark applies to our subsequent analysis as well; one can obtain sharper comparative static results on shares of the material surplus than those on shares of the material output.

\subsubsection{The Impact of Household Roles}

To investigate the impact of household roles, we start again at the benchmark equilibrium and examine the impact of an increase in $\tau$, holding the wages of men and women at their benchmark values, that is $w_{1}^{m}=w_{1}^{w}=w_{1}$ and $w_{2}^{m}=w_{2}^{w}=w_{2}$. Initially, assume that due to norms the wife alone spends time on child care. Then an increase in the requirements for child care reduces the contribution that educated women make to marital output and raises the contribution of uneducated women. That is, $z_{11}$ and $z_{21}$ rise because uneducated women are more productive at home, $\gamma>w_{1}$, while $z_{12}$ and $z_{22}$ decline because educated women are less productive at home, $\gamma<w_{2}$. Consequently, both equilibrium lines corresponding to conditions (21) and (22) shift down so that $V_{2}$ is lower for any $V_{1}$ and the analysis is the same as in the previous case. The only difference is that the boundaries on the rate of returns from schooling that men can obtain within marriage shift as $z_{21}-z_{11}$ rises and $z_{22}-z_{12}$ 
declines.

For moderate changes in $\tau$, strictly positive assortative mating with equal sharing continues to hold. As long as a symmetric equilibrium is maintained, the returns to schooling that men and women receive within marriage, $V_{2}-V_{1}$ and $U_{2}-U_{1}$, are equal. Hence, men and women have the same incentives to invest. But because the material surplus (and consequently utilities within marriage) of educated men and women, $z_{22} / 2$, declines with $\tau$, while the material surplus of uneducated men and women, $z_{11} / 2$, rises, both men and women will reduce their investments in schooling by the same degree.

As $\tau$ rises further, the difference in the contributions of men and women to marriage can rise to the extent that an educated man contributes to a marriage with uneducated woman more than an educated woman contributes to a marriage with an educated man. That is, $z_{21}-z_{11}>z_{22}-z_{21}$, implying that the lower bound on the return to schooling that men receive within marriage exceeds the upper bound on the return to schooling that woman receive within marriage. ${ }^{13}$ In this event, the symmetric equilibrium is eliminated and instead there is a mixed equilibrium with some educated men marrying uneducated women. This outcome reflects the lower incentive of educated women to enter marriage and the stronger incentive of men to invest because their return from schooling within marriage, $V_{2}-V_{1}=z_{21}-z_{11}$, exceeds the return to schooling that women can obtain in marriage. Consequently, some educated men must "marry down" and match with uneducated women.

An important idea of Becker (1991, Ch. 2) is that wage differences among identical spouses can be created endogenously and voluntarily because of learning by doing and increasing returns. Thus, it may be optimal for the household for one of the spouses to take care of the child and for the other to enter the labor market. Because we assume transferable utility between spouses, household roles will be determined efficiently by each married couple as long as there is ability to commit to a transfer scheme, whereby the party that sacrifices outside options when he $\backslash$ she acts in a manner that raises the total surplus is compensated for his/her action. In the previous analysis, there was no need for such a commitment because the division of the surplus was fully determined by attributes that were determined prior to marriage via competition over mates who could freely replace partners. However, if time spent on child care affects one's labor

\footnotetext{
${ }^{13}$ Equal wages of men and women imply $z_{12}=z_{21}$ and

$$
\begin{aligned}
& h\left(w_{1}, w_{2}, \tau\right) \equiv 2 z_{21}-z_{11}-z_{22}=2\left[w_{2}+\tau \gamma+(1-\tau) w_{1}\right]^{2} \\
& -\left[w_{1}+\tau \gamma+(1-\tau) w_{1}\right]^{2}-\left[w_{2}+\tau \gamma+(1-\tau) w_{2}\right]^{2} .
\end{aligned}
$$
}

For $w_{1}$ slightly below $\gamma$ and $w_{2}$ slightly above $\gamma, h\left(w_{1}, w_{2}, \tau\right)>0$. The larger is $\tau$, the broader will be the range in which $h\left(w_{1}, w_{2}, 0\right)>0$. 
market wages subsequently, the cost of providing childcare can differ between the two spouses. Then, implementing the efficient outcome might require some form of commitment even if (re)matching is frictionless (see Lundberg and Pollak, 1993, and Lundberg, 2005). A simple, enforceable, prenuptial contract is one in which both partners agree to pay the equilibrium shares $V_{I}$ to the husband and $U_{J}$ to the wife in case of divorce. By making those shares the relevant threat points of each spouse, this contract sustains the equilibrium values $V_{I}$ and $U_{J}$ in marriage, which is sufficient to attain the efficient household division of labor.

If there is discrimination against women in the labor market and they receive lower wages than men, partners that act efficiently will typically assign the wife to stay at home, which will erode her future market wage and reinforce the unequal division of labor. Similarly, if there are predetermined household roles such that women must take care of their child, then women will end up with lower market wages. Thus, inequality at home and the market are interrelated ( see Albanesi and Olivetti, 2005, and Chichilnisky, 2005).

\subsection{Why Women May Acquire More Schooling than Men}

We have examined two possible reasons why women may invest differently from men: the first is difference in market returns for schooling and the second is a difference in the returns for schooling within marriage. We now proceed to more specific assumptions to address the puzzling reversal in the gender differences in schooling, starting at about 1980. Consider a comparison of the following two situations. An "old" regime in which married women must spend a relatively large fraction of their time at home and a "new" regime in which, because of reductions in fertility and improved technology in home production, married women spend less time at home and work more in the market (Greenwood et al., 2005). Assume further that women suffer from statistical discrimination because employers still expect them to invest less on the job. Assume, however, that discrimination is weaker against educated women because they are expected to stay longer in the labor market than uneducated women. Finally, assume that in the old regime norms were relevant but in the new regime household roles are determined efficiently. It is then possible that in the new regime women will invest in schooling more than men. The presence of discrimination raises the return of women relative to men because schooling serves as an instrument for women to escape discrimination. The fact that women are still tied up in home work lowers their return from schooling relative to men because women obtain lower returns from schooling within marriage. However, as women increase their labor force participation, due to technological changes or a shift in norms, this second effect 
weakens and the impact of discrimination can dominate. ${ }^{14}$

In Figure 8, we display the transition between the two regimes. We assume that discrimination against women is lower at the higher level of schooling in both regimes. However, in the first regime, women must spend substantial amount of time working at home, implying that, within marriage, women receive lower returns to schooling than men. Thus men have stronger incentives to acquire schooling, and to sharpen our result we assume a mixed initial mixed equilibrium (point el Figure 8) such that the return that men receive within marriage is at the lower bound and some educated men marry with uneducated women. We then reduce the amount of time that the mother has to spend at home, $\tau$, and raise the wage that educated women receive (so that $w_{2}^{w} / w_{1}^{w}$ rises), which strengthens the incentives of women to invest in schooling and to marry. Therefore, holding the marriage surplus $z_{I J}$ constant, an increase in $V_{2}$ relative to $V_{1}$ is required to maintain equality between the number of men who wish to invest and marry and the number of women who wish to invest and marry. This effect is represented by the upwards shifts in the broken lines in Figure $8 .{ }^{15}$ The impact is assumed to be large enough to generate a new mixed equilibrium in which returns from schooling that men can receive within marriage is at the upper bound, implying that women receive the lower bound on the her returns for schooling within marriage. This new mixed equilibrium is indicated by the point $e^{\prime \prime}$ in Figure 8 .

This exercise illustrates how the economy can switch from a situation in which men invest more in schooling and some educated men marry down to a new equilibrium in which women invest more in schooling and some of them marry down. Simple simulations show that such a transition is associated with an increase in the proportion of educated women that marry, as educated women are released from household chores and increase their investment in schooling. Therefore, the proportion of couples in which the wife is more educated than the husband rises. Men anticipate that they will be less likely to be the sole "breadwinner" in the family and reduce their investment in schooling. Divisions of the surplus within marriage also adjust to these changes; uneducated men gain a higher share in the surplus in all marriages because of their new opportunity to marry educated women, while uneducated women lose part of

\footnotetext{
${ }^{14}$ Models of statistical discrimination tie household roles and market wages through employers' beliefs about female participation. Typically, such models generate multiple equilibria and inefficiency (Hadfield, 1999, Lommerud and Vagstad, 2002). Here, we do not require employers' beliefs to be correct. Instead, we think of household roles and discrimination as processes that evolve slowly and can be taken as exogenous in the medium run.

${ }^{15}$ Because the marital surplus matrix, $z_{I J}$, also changes, it is not always the case that the equilibrium curves shift up. For the parameters of Figure 8 (see Browning et al., 2007), there is a range where the line representing the equilibrium condition (21) shifts down. This, however, has no bearing on the equilibrium outcome.
} 
their share in the marital surplus in all marriages because they no longer marry educated men. The impact of the changes in household production and market returns are of course stronger, if they are accompanied by a change in norms, such that in the new regime couples act efficiently and educated women anticipate to work in the market.

\section{Conclusions}

In standard models of human capital, individuals invest in schooling with the anticipation of being employed at a higher future wage that would compensate them for the current foregone earnings. In this paper, we add another consideration: the anticipation of being married to a spouse with whom one can share consumption and coordinate work activities. Schooling has an added value in this context because of complementarity between agents, whereby the contribution of the agents' schooling to marital output rises with the schooling of their spouses. In the frictionless marriage market considered here, the matching pattern is fully predictable and supported by a unique distribution of marital gains between partners. Distribution is governed by competition, because for each agent there are perfect substitutes that can replace him $\backslash$ her in marriage. There is thus no scope for bargaining and, therefore, premarital investments are efficient. This simple framework allows us to jointly determine investment and marriage patterns as well as the welfare of men and women under a variety of circumstances.

From the perspective of family economics, gender differences in investment in schooling are of particular interest because assortative matching based on schooling is a common feature of marriage patterns in modern societies. However, schooling is an acquired trait that responds to economic incentives. We mentioned two interrelated causes that may diminish the incentives of women to invest in schooling: lower market wages and larger amount of household work. Although we did not fully specify the sources of discrimination against women in the market, we noted that such discrimination tends to decline with schooling and therefore increases the incentive to invest. This is a possible explanation for the slightly higher investment in schooling by women that we observe today. We do not view this outcome as a permanent phenomenon but rather as a part of an adjustment process, whereby women who now enter the labor market in increasing numbers following technological changes at home and in the market that favor women, must be "armed" with additional schooling to overcome norms and beliefs that originated in the past.

From the perspective of labor economics, the introduction of family considerations 
can broaden our analysis of the incentive to invest in human capital. Early work by Mincer and Polachek (1974) provided explanations for the gender wage gap even in the absence of any discrimination based on lower investments on the job resulting from expected interruptions in labor force participation. At that time, women also acquired less schooling. The current reversal in the schooling gender gap poses a challenge to this approach. 


\section{Appendix: Existence and Uniqueness of Equi- librium}

Substitute $z_{11}-V_{1}$ for $U_{1}$ and $z_{22}-V_{2}$ for $U_{2}$ in equation $(21)$, and define $\Psi\left(V_{1}, V_{2}\right)$ as

$$
\begin{aligned}
\Psi\left(V_{1}, V_{2}\right) \equiv & F\left(V_{1}\right)+\int_{V_{1}}^{V_{2}} G\left(R^{m}+V_{2}-\theta\right) f(\theta) d \theta \\
& -F\left(z_{11}-V_{1}\right)-\int_{z_{11}-V_{1}}^{z_{22}-V_{2}} G\left(R^{w}+z_{22}-V_{2}-\theta\right) f(\theta) d \theta .
\end{aligned}
$$

Note, first, that

$$
\Psi(0,0)=F(0)-F\left(z_{11}\right)-\int_{z_{11}}^{z_{22}} G\left(R^{w}+z_{22}-\theta\right) f(\theta) d \theta<0
$$

and that

$$
\Psi\left(z_{11}, z_{22}\right) \equiv F\left(z_{11}\right)-F(0)+\int_{z_{11}}^{z_{22}} G\left(R^{m}+z_{22}-\theta\right) f(\theta) d \theta>0
$$

since $z_{11}>0$ implies that $F\left(z_{11}\right)-F(0)>0$. By continuity, we conclude that there exists a set of couples $\left(V_{1}, V_{2}\right)$ for which $\Psi\left(V_{1}, V_{2}\right)=0$.

In addition, we have

$$
\begin{aligned}
\frac{\partial \Psi\left(V_{1}, V_{2}\right)}{\partial V_{1}}=f\left(V_{1}\right)[ & \left.-G\left(R^{m}+V_{2}-V_{1}\right)\right] \\
& +f\left(z_{11}-V_{1}\right)\left[1-G\left(R^{w}+z_{22}-z_{11}-\left(V_{2}-V_{1}\right)\right]>0\right.
\end{aligned}
$$

and

$$
\begin{aligned}
\frac{\partial \Psi\left(V_{1}, V_{2}\right)}{\partial V_{2}}=G\left(R^{m}\right) & \left.f\left(V_{2}\right)+G\left(R^{w}\right) f\left(z_{22}-V_{2}\right)\right] \\
& +\int_{V_{1}}^{V_{2}} g\left(R^{m}+V_{2}-\theta\right) f(\theta) d \theta+\int_{U_{1}}^{U_{2}} g\left(R^{w}+U_{2}-\theta\right) f(\theta) d \theta>0 .
\end{aligned}
$$


By the implicit function theorem, $\Psi\left(V_{1}, V_{2}\right)=0$ defines $V_{2}$ as a differentiable, decreasing function of $V_{1}$ over some open set in $\mathbb{R}$. Equivalently, the locus $\Psi\left(V_{1}, V_{2}\right)=$ 0 defines a smooth, decreasing curve in the $\left(V_{1}, V_{2}\right)$ plane.

Using (22), define $\Omega\left(V_{1}, V_{2}\right)$ as

$$
\begin{aligned}
\Omega\left(V_{1}, V_{2}\right) \equiv & F\left(V_{1}\right)\left[1-G\left(R^{m}+V_{2}-V_{1}\right)\right] \\
& -F\left(z_{11}-V_{1}\right)\left[1-G\left(R^{w}-z_{11}+V_{1}+z_{22}-V_{2}\right)\right] .
\end{aligned}
$$

Note that $\Omega$ is continuously differentiable, increasing in $V_{1}$ and decreasing in $V_{2}$. Moreover,

$$
\begin{aligned}
& \lim _{V_{1} \rightarrow \infty} \Omega\left(V_{1}, V_{2}\right)=1, \\
& \lim _{V_{2} \rightarrow \infty} \Omega\left(V_{1}, V_{2}\right)=-F\left(z_{11}-V_{1}\right)<0 .
\end{aligned}
$$

By continuity, there exists a locus on which $\Omega\left(V_{1}, V_{2}\right)=0$; by the implicit function theorem, it is a smooth, increasing curve in the $\left(V_{1}, V_{2}\right)$ plane. In addition,

$$
\Omega\left(V_{1}, V_{2}\right)=A\left(V_{1}, V_{2}-V_{1}\right)
$$

where

$$
A(V, X)=F(V)\left[1-G\left(R^{m}+X\right)\right]-F\left(z_{11}-V\right)\left[1-G\left(R^{w}-z_{11}+z_{22}-X\right)\right] .
$$

Since

$\frac{\partial A(V, X)}{\partial V}=f(V)\left[1-G\left(R^{m}+X\right)\right]+f\left(z_{11}-V\right)\left[1-G\left(R^{w}-z_{11}+z_{22}-X\right)\right]>0$

and

$$
\frac{\partial A(V, X)}{\partial X}=-F(V) g\left(R^{m}+X\right)-F\left(z_{11}-V\right) g\left(R^{w}-z_{11}+z_{22}-X\right)<0
$$

the equation $A(V, X)=0$ defines $X$ as some increasing function $\phi$ of $V$. Therefore,

$$
\Omega\left(V_{1}, V_{2}\right)=A\left(V_{1}, V_{2}-V_{1}\right)=0
$$

gives

$$
V_{2}=V_{1}+\phi\left(V_{1}\right)
$$

where $\phi^{\prime}(V)>0$. Thus in the $\left(V_{1}, V_{2}\right)$ plane, the slope of the $\Omega\left(V_{1}, V_{2}\right)=0$ curve is always more than 1 . In particular, the curve must intersect the decreasing curve $\Psi\left(V_{1}, V_{2}\right)=0$, and this intersection $\left(V_{1}^{*}, V_{2}^{*}\right)$ is unique.

Finally, stability requires that

$$
U_{1}+V_{2} \geq z_{21} \quad \text { and } \quad U_{2}+V_{1} \geq z_{12}
$$


which implies that, at any stable match, we have

$$
z_{21}-z_{11} \leq V_{2}-V_{1} \leq z_{22}-z_{12}
$$

and

$$
z_{12}-z_{11} \leq U_{2}-U_{1} \leq z_{22}-z_{21} .
$$

Three cases are thus possible:

1. If $z_{21}-z_{11} \leq V_{2}^{*}-V_{1}^{*} \leq z_{22}-z_{12}$, then $\left(V_{1}^{*}, V_{2}^{*}\right)$ is the unique equilibrium (see Figure A.1). Indeed, it is the only equilibrium with perfectly assortative matching. Moreover, a point such that

$$
\Psi\left(V_{1}, V_{2}\right)=0 \quad \text { and } \quad V_{2}-V_{1}=z_{21}-z_{11}
$$

cannot be an equilibrium, because at that point $\Omega\left(V_{1}, V_{2}\right)>0$, which contradicts the fact that the number of educated men should exceed that of educated women for such an equilibrium to exist. Similarly, a point such that

$$
\Psi\left(V_{1}, V_{2}\right)=0 \quad \text { and } \quad V_{2}-V_{1}=z_{22}-z_{12}
$$

cannot be an equilibrium, because at that point $\Omega\left(V_{1}, V_{2}\right)<0$, which contradicts the fact that the number of educated women should exceed that of educated men for such an equilibrium to exist.

2. If $z_{21}-z_{11}>V_{2}^{*}-V_{1}^{*}$, then the unique equilibrium (see Figure A.2) is such that

$$
\Psi\left(V_{1}, V_{2}\right)=0 \quad \text { and } \quad V_{2}-V_{1}=z_{21}-z_{11} .
$$

Indeed, a perfectly assortative matching equilibrium is not possible because the only possible candidate, $\left(V_{1}^{*}, V_{2}^{*}\right)$, violates the condition $z_{21}-z_{11} \leq V_{2}^{*}-V_{1}^{*} \leq$ $z_{22}-z_{12}$. And a point such that

$$
\Psi\left(V_{1}, V_{2}\right)=0 \quad \text { and } \quad V_{2}-V_{1}=z_{22}-z_{12}
$$

cannot be an equilibrium, because at that point $\Omega\left(V_{1}, V_{2}\right)<0$ which contradicts the fact that the number of educated women should exceed that of educated men for such an equilibrium to exist.

3. Finally, if $V_{2}^{*}-V_{1}^{*}>z_{22}-z_{12}$, then the unique equilibrium (see Figure A.3) is such that

$$
\Psi\left(V_{1}, V_{2}\right)=0 \quad \text { and } \quad V_{2}-V_{1}=z_{22}-z_{12} .
$$

Indeed, a perfectly assortative matching equilibrium is not possible because the only possible candidate, $\left(V_{1}^{*}, V_{2}^{*}\right)$, violates the condition $z_{21}-z_{11} \leq V_{2}^{*}-V_{1}^{*} \leq$ $z_{22}-z_{12}$. And a point such that

$$
\Psi\left(V_{1}, V_{2}\right)=0 \quad \text { and } \quad V_{2}-V_{1}=z_{21}-z_{11}
$$

cannot be an equilibrium, because at that point $\Omega\left(V_{1}, V_{2}\right)>0$ which contradicts the fact that the number of educated men should exceed that of educated women for such an equilibrium to exist. 


\section{References}

[1] Albanesi, S. and C. Olivetti. (2005). "Home Production, Market Production and the Gender Wage Gap: Incentives and Expectations," CEPR Discussion Paper No: 4984, December.

[2] Angrist, J. (2002). "How Do Sex Ratios Affect Marriage and Labor Markets? Evidence from America's Second Generation," Quarterly Journal of Economics, August, 997-1038.

[3] Ariely, D., G. Hitsch, and A. Hortacsu. (2006). "What Makes You Click? Mate Preferences and Matching Outcomes in Online Dating." University of Chicago, unpublished manuscript.

[4] Baker, M. and J. Jacobsen. (2007). "Marriage, Specialization, and the Gender Division of Labor," Journal of Labor Economics, 25 (4), October, 763-793.

[5] Becker G. (1991). Treatise on the Family, Harvard University Press.

[6] Behrman, J. R. (1997). "Mother's Schooling and Child Education: A Survey" PIER Working Paper No: 97-024.

[7] Browning, M., P. A. Chiappori, and Y. Weiss. (in progress). Family Economics, (Cambridge: Cambridge University Press).

[8] Charles, K. and M. Luoh. (2003), "Gender Differences in Completed Schooling," The Review of Economics and Statistics, 85, 559-577.

[9] Chiappori, P. and Y. Weiss. (2007), "Divorce, Remarriage and Child Support," Journal of Labor Economics, 25, 37-74 .

[10] Chiappori, P. A., B. Fortin, and G. Lacroix. (2002). "Marriage Market, Divorce Legislation, and Household Labor Supply," Journal of Political Economy, $110(1), 37-72$.

[11] Chichilnisky, G. (2005). "The Gender Gap," Columbia University, unpublished manuscript.

[12] Choo, E. and A. Siow. (2006). "Lifecycle marriage matching: Theory and evidence," University of Toronto, unpublished manuscript.

[13] Cole, H., G. Mailath and A. Postlewaite. (2001). "Efficient Non Contractible Investments in Large Economies," Journal of Economic Theory, 101, 333-373.

[14] Del Boca, D. and C. Flinn. (2006). "Household Time Allocation and Modes of Behavior: A Theory of Sorts," New York University, unpublished manuscript. 
[15] Dougherty, C. (2005). "Why is the Return to Schooling Higher for Woman Than For Men?" Journal of Human Resources, 40, 969-988.

[16] Goldin, C. L. Katz and I. Kuziemko. (2006). "The Homecoming of American College Women: A Reversal of the College Gender Gap," Journal of Economic Perspectives, 20:4, Fall, 133-56.

[17] Gosling, A. (2003), " The changing Distribution of Male and Female Wages 1978-2000: Can Simple Skill Story be Rejected?" CEPR Discussion Paper 3787.

[18] Greenwood, J. A. Seshadri, and M. Yorukoglu. (2005). "Engines of Liberation," Review of Economic Studies, 72, 109-33.

[19] Grossbard-Shechtman, S. (1995). "Marriage Market Models," in M. Tomassi and K. Ierulli (eds.), The New Economics of Human Behavior. (Cambridge: Cambridge University Press).

[20] Hadfield, G. (1999). "A Coordination Model of Sexual Division of Labor," Journal of Economic Behavior and Organization, 40, 125-53.

[21] Iyigun, M. and R. Walsh. (2007). "Building the Family Nest: Pre-Marital Investments, Marriage Markets and Spousal Allocations," Review of Economic Studies, 74:2, April, 507-35.

[22] Katz, L. and D. Autor. (1999). "Changes in the Wage Sructure and Earning Inequality," in O. Ashenfelter and D. Card (eds.) Handbook of Labor Economics, Amsterdam, Elsevier.

[23] Lommerud, K. and E. Vagstad. (2000). "Mommy Tracks and Public Policy; On Self Fulfilling Prophecies and Gender Gaps in Promotion," CEPR Discussion Paper 2378.

[24] Lundberg, S. and R. A. Pollak. (1993). "Separate Spheres Bargaining and the Marriage Market," Journal of Political Economy, 101 (6), 988-1010.

[25] Mincer, J and S. Polachek. (1974). "Family Investments in Human Capital: Earnings of Women," Journal of Political Economy, 82, s76-s R108.

[26] Peters, M. and A. Siow. (2002). "Competing Premarital Investments," Journal of Political Economy, 110, 592-208.

[27] Seitz, S. (2002). "Labor Supply, Divorce and Remarriage," Boston College, unpublished manuscript.

[28] Shapley, L. and M. Shubik. (1972). "The Assignment Game I; the Core," International Journal of Game Theory, 1, 111-130. 
Figure 1: Regions for Marriage and Investment

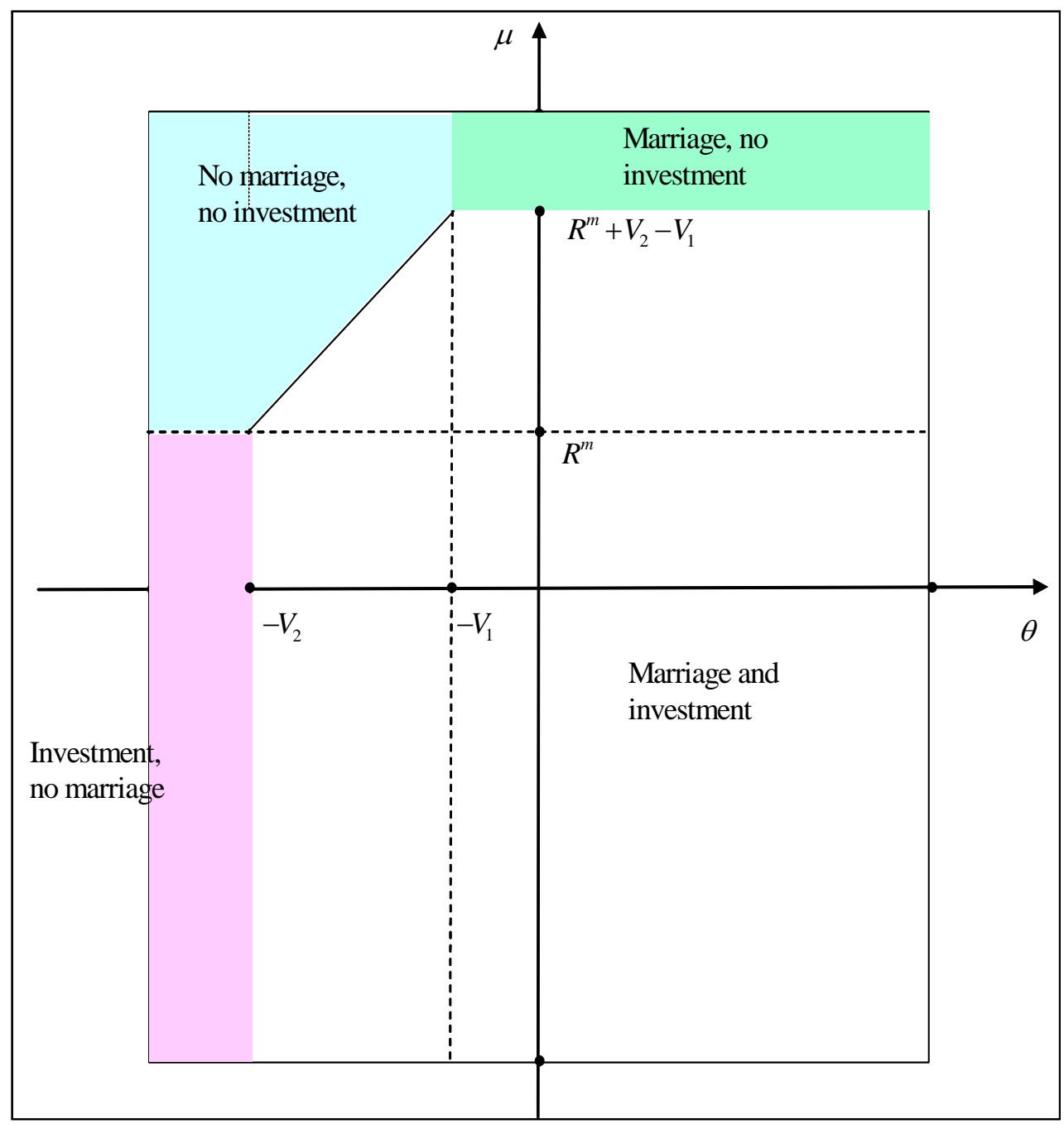


Figure 2: Equilibrium with Strictly Positive Assortative Matching

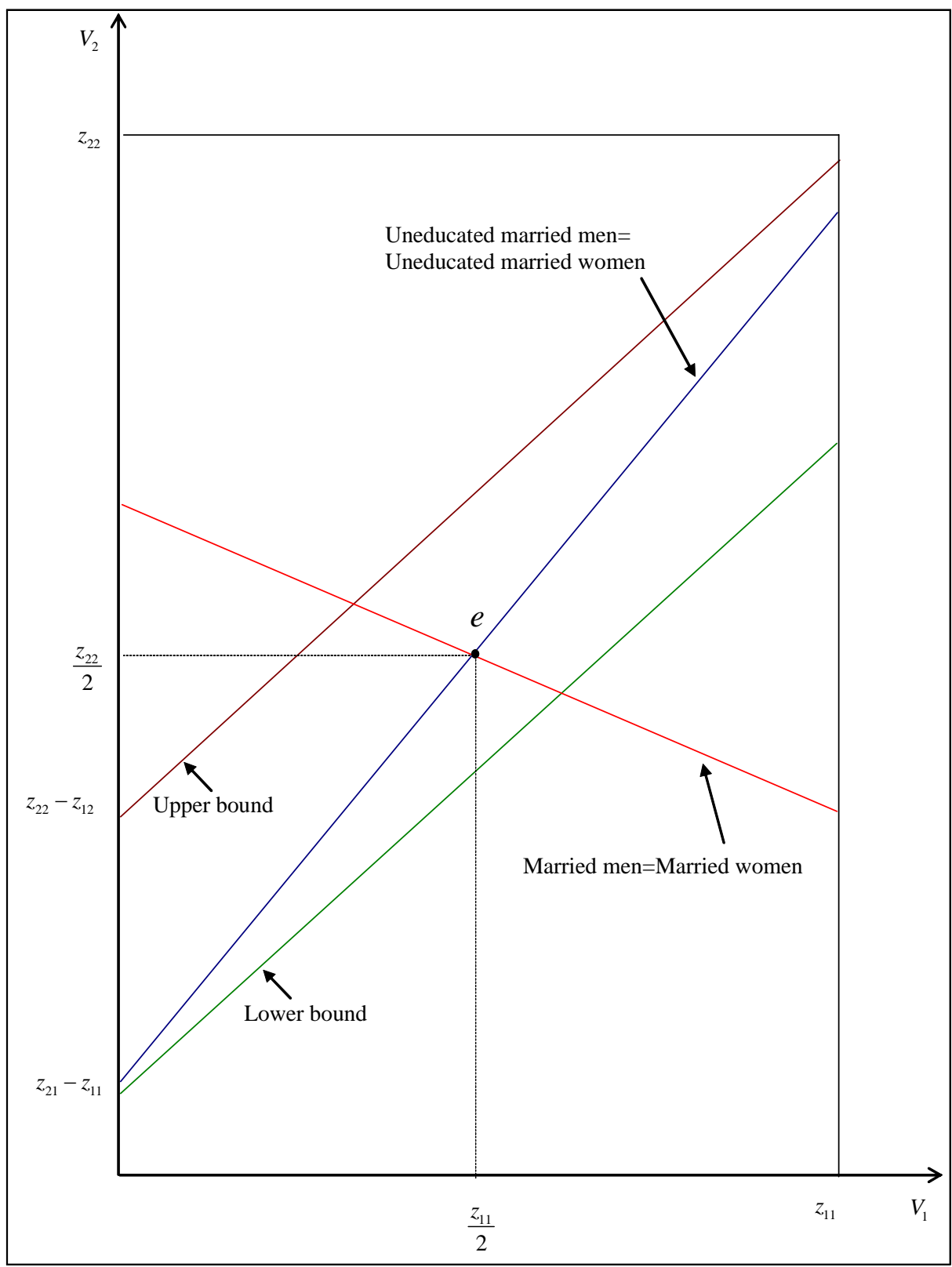


Figure 3: Mixed Equilibrium with More Educated Men than Educated Women

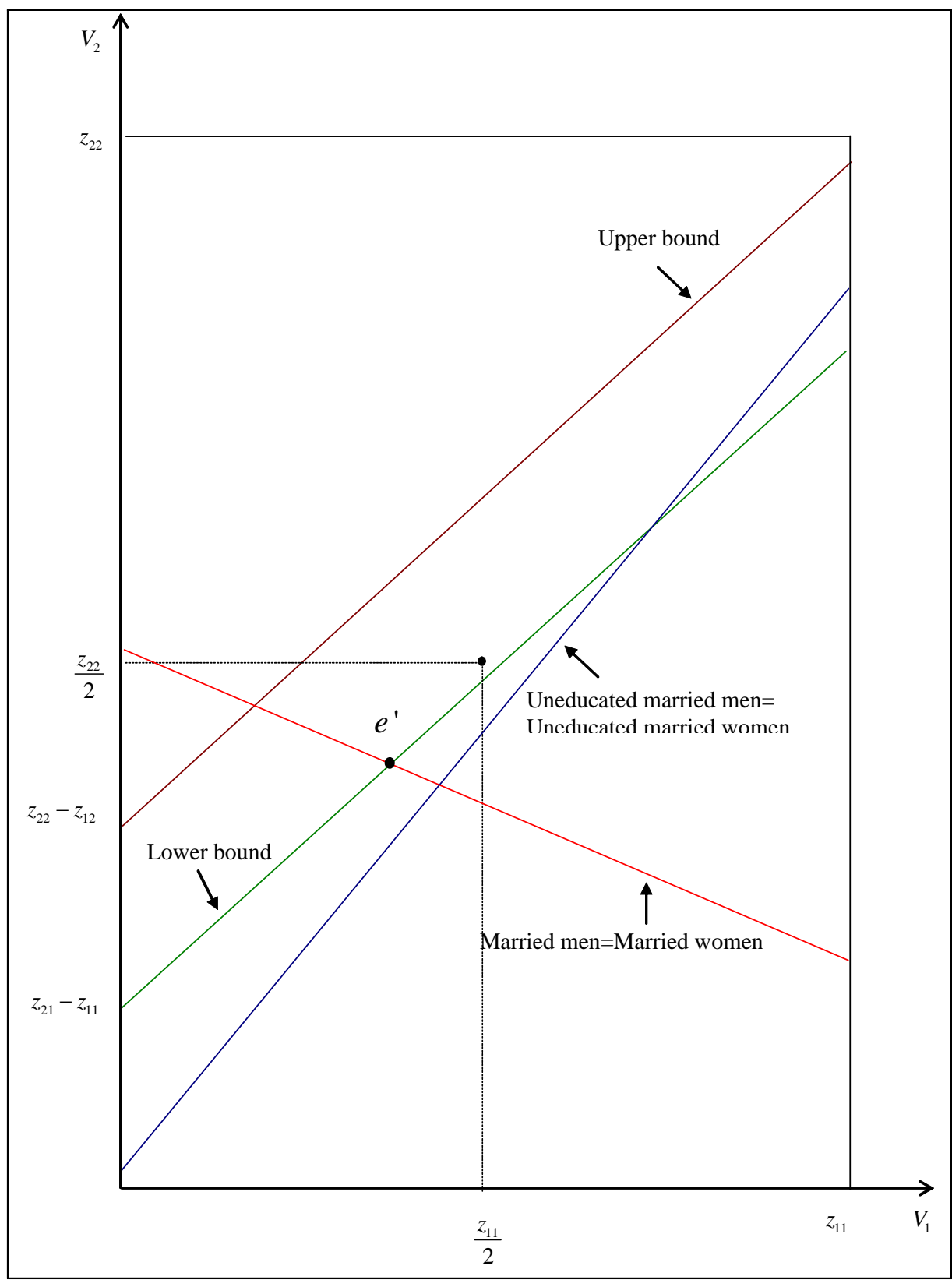


Figure 4: Completed Education by Sex, 30-40 years old, US 1968-2005 (CPS)

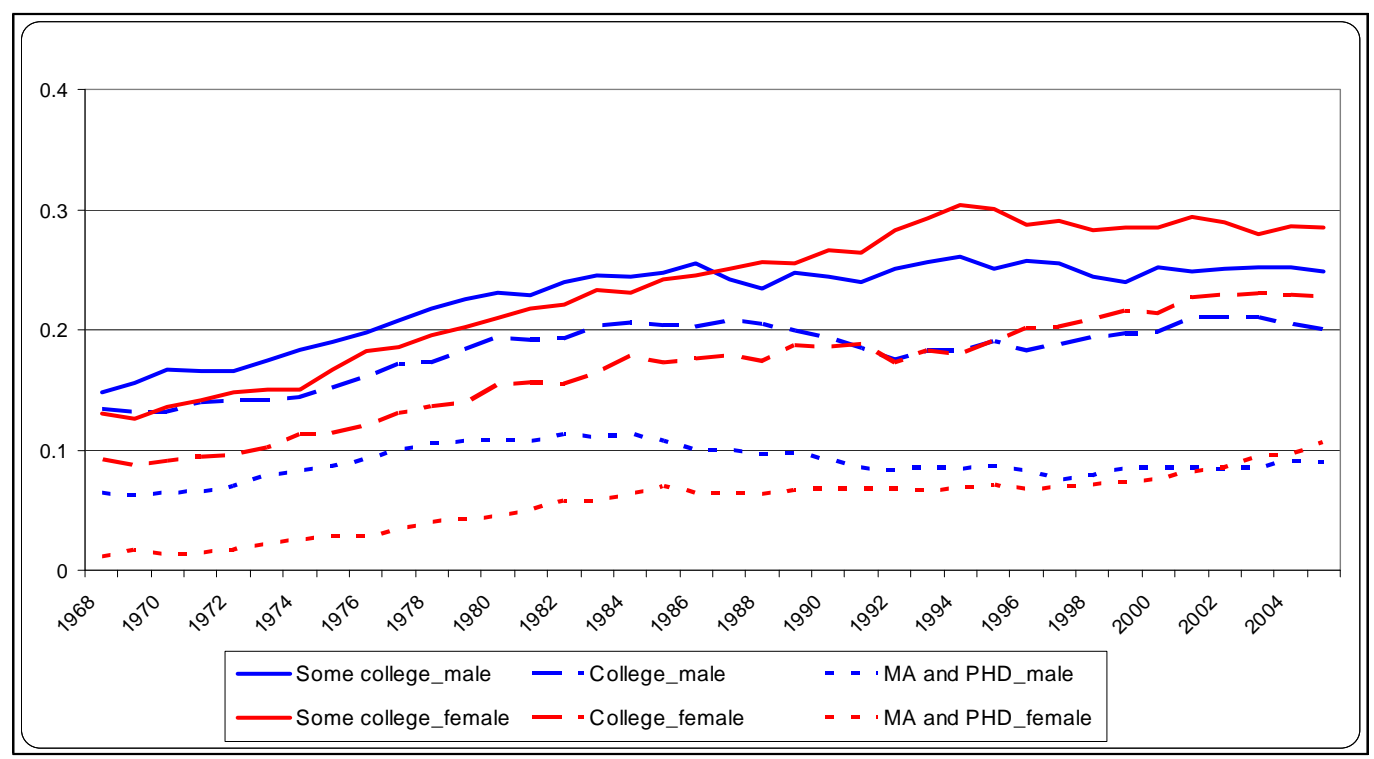

Source: Current Population Surveys.

Figure 5: Educational Attainment of Spouses by Husbands' Year of Birth (United States)

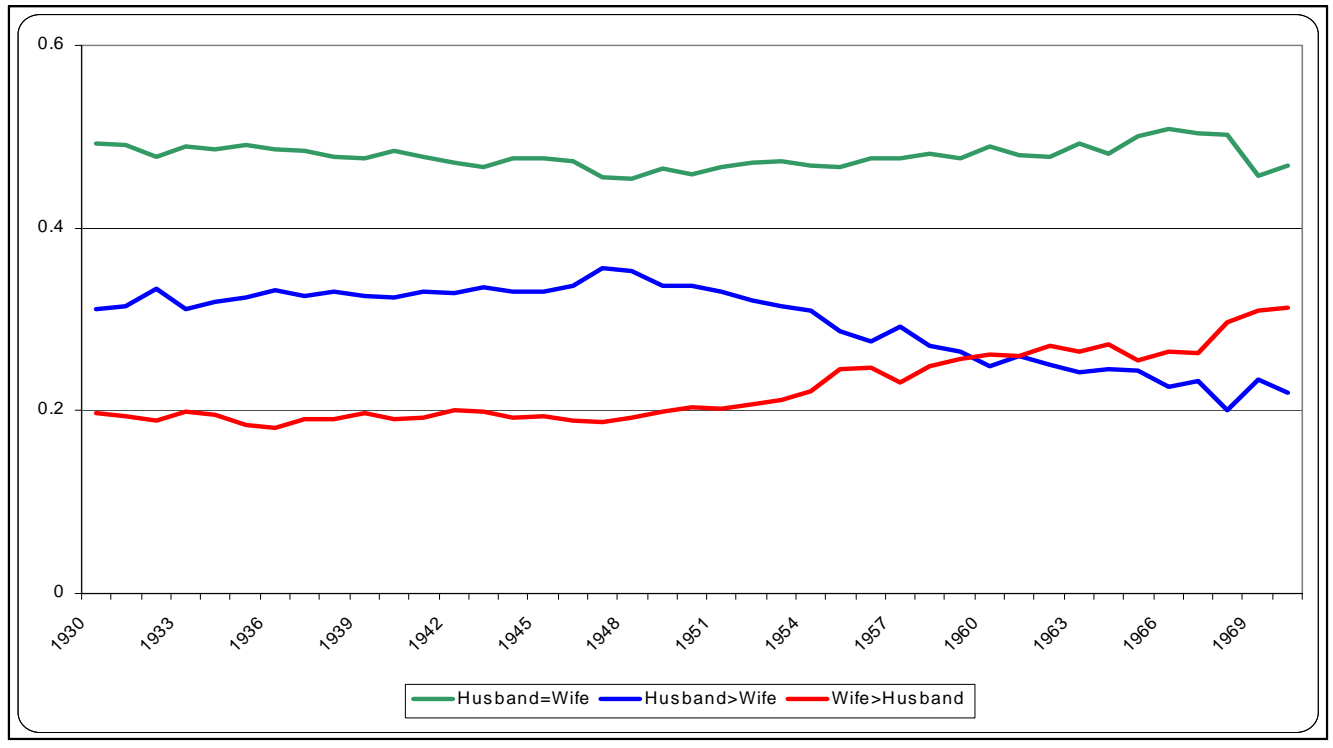

Source: Current Population Surveys. 
Figure 6: Couples' Work Patterns by Spousal Education, Ages 30-40, U. S., 1976-80 and 2001-05

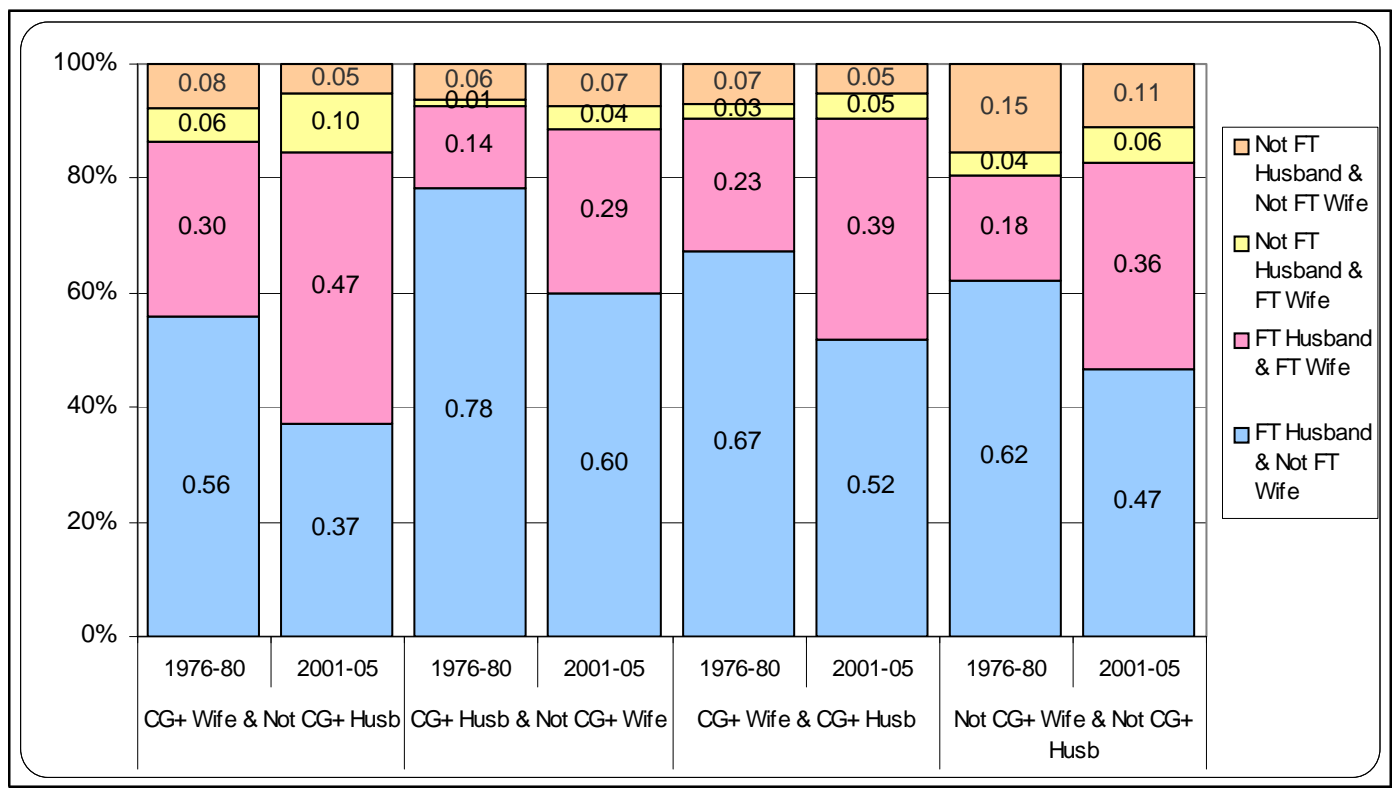

Source: Current Population Surveys.

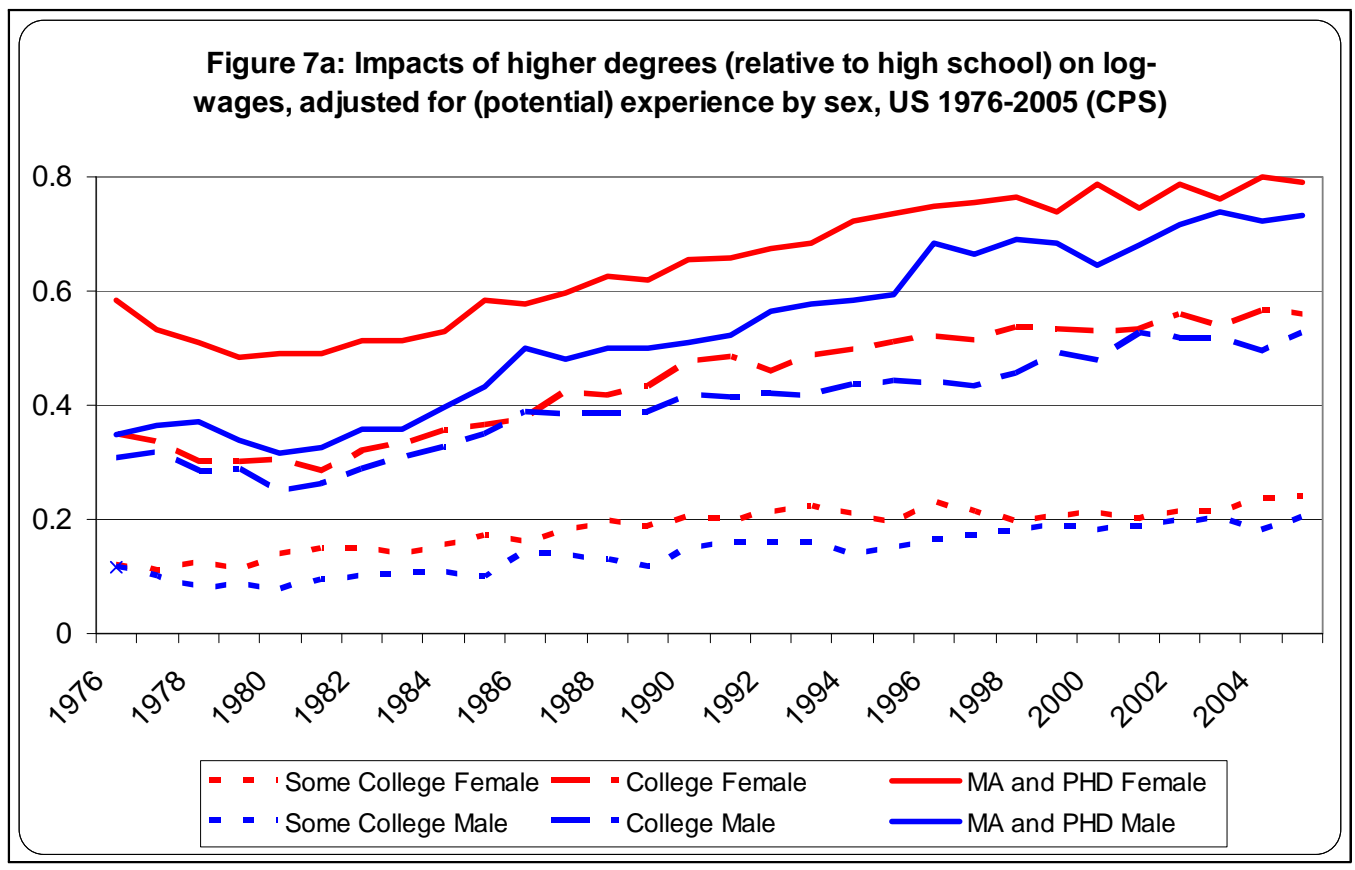



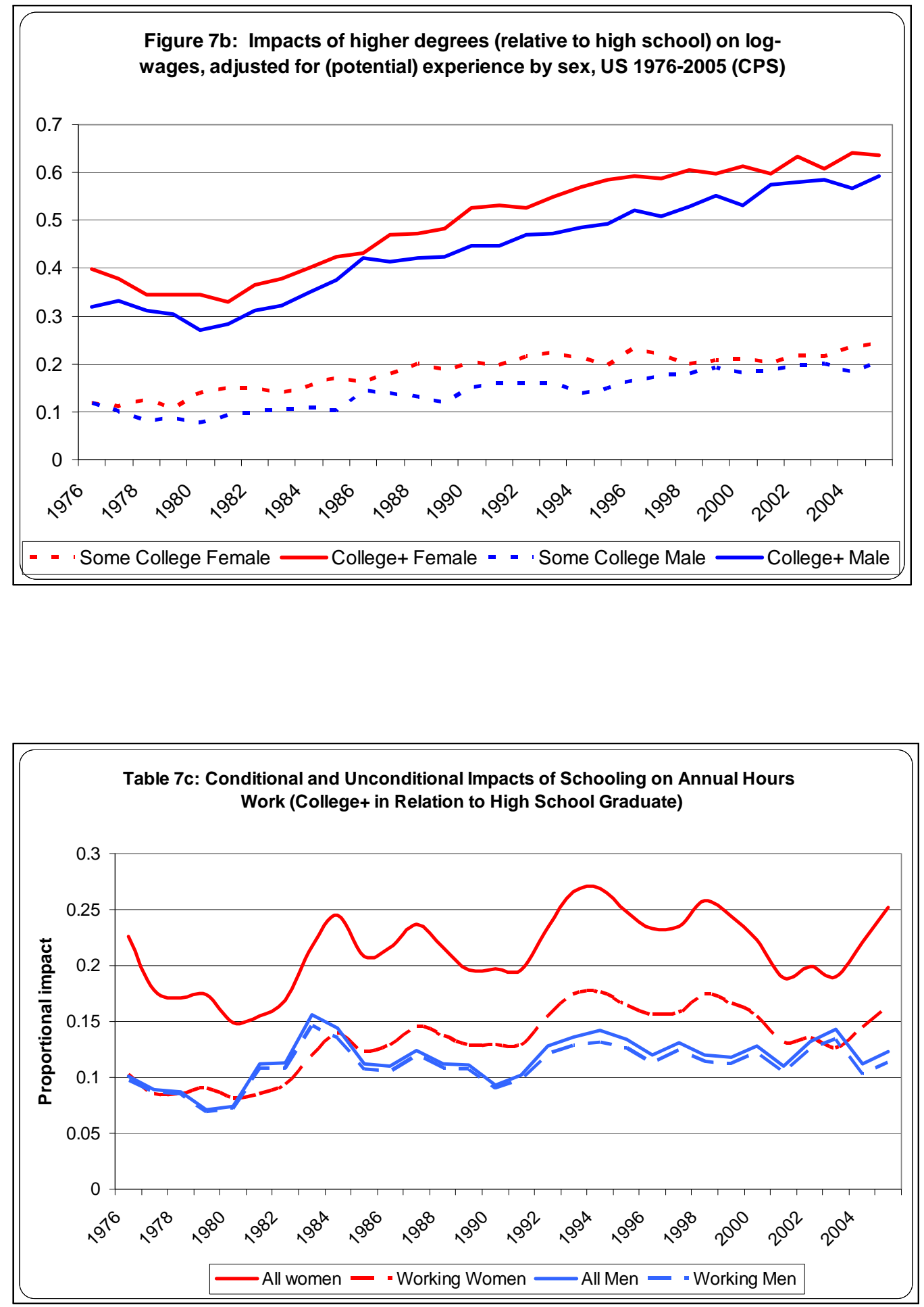
Figure 8: The Impact of a Decrease in the Wife's Work at Home Combined with an Increase in the Wage of Educated Women

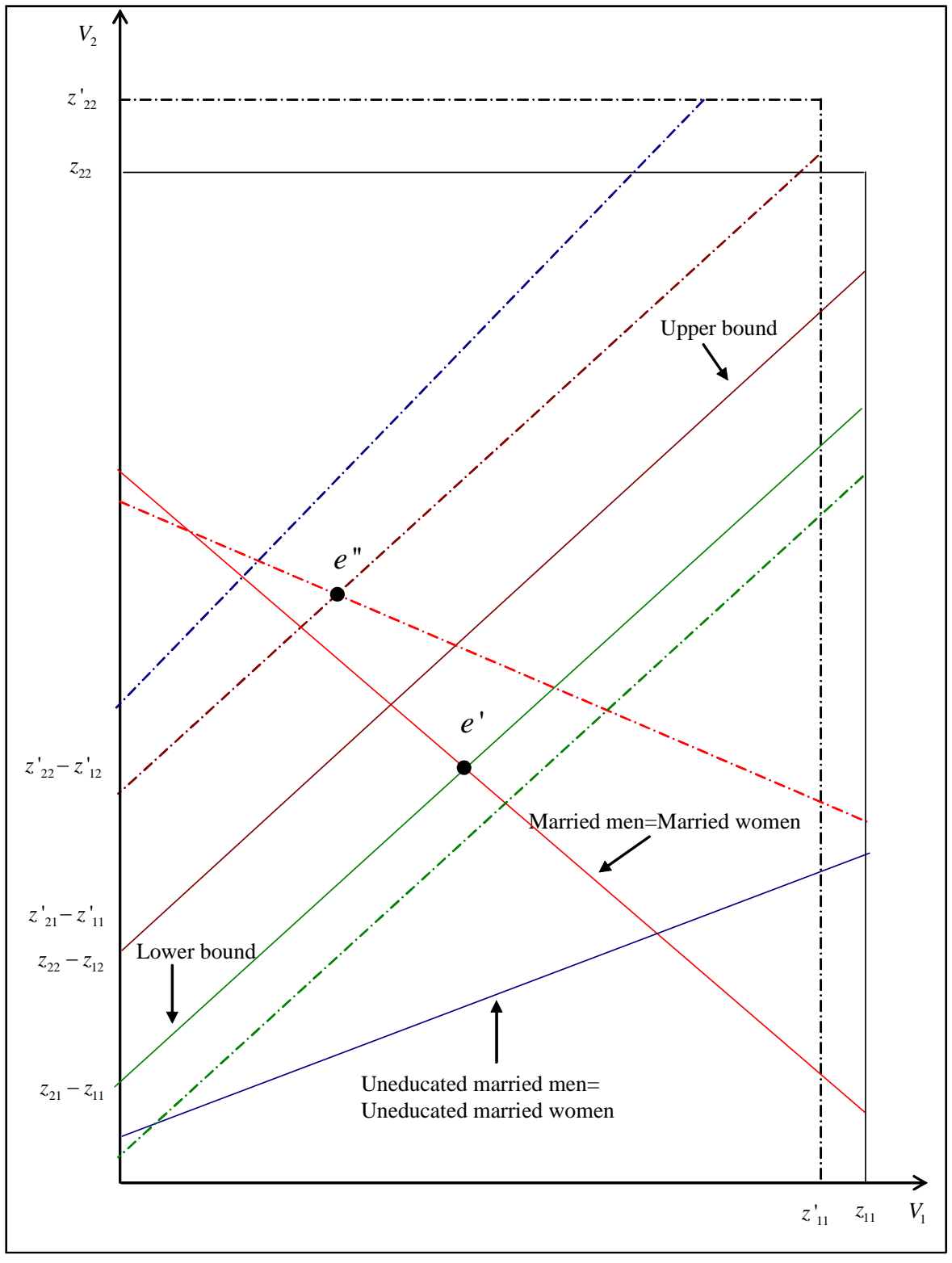


Table 1: Time Use (hours per day) of US Married Men and Women with Children

\begin{tabular}{|c|c|c|c|c|}
\hline & \multicolumn{2}{|c|}{1975} & \multicolumn{2}{|c|}{2003} \\
\hline & Women & Men & Women & Men \\
\hline Paid work & & & & \\
\hline Child $<5$ & 1.55 & 6.98 & 2.81 & 6.39 \\
\hline Child 5-17 & 2.71 & 7.17 & 3.68 & 6.40 \\
\hline Household Work & & & & \\
\hline Child $<5$ & 3.67 & 1.10 & 2.64 & 1.38 \\
\hline Child 5-17 & 3.63 & 1.18 & 2.83 & 1.52 \\
\hline Child Care & & & & \\
\hline Child <5 & 1.63 & 0.40 & 2.67 & 1.24 \\
\hline Child 5-17 & 0.65 & 0.20 & 1.13 & 0.57 \\
\hline Shopping & & & & \\
\hline Child $<5$ & 0.50 & 0.28 & 0.60 & 0.39 \\
\hline Child 5-17 & 0.59 & 0.24 & 0.61 & 0.34 \\
\hline Leisure & & & & \\
\hline Child $<5$ & 5.98 & 5.43 & 5.01 & 4.93 \\
\hline Child 5-17 & 6.14 & 5.38 & 5.61 & 5.49 \\
\hline
\end{tabular}




\section{Appendix Figures}
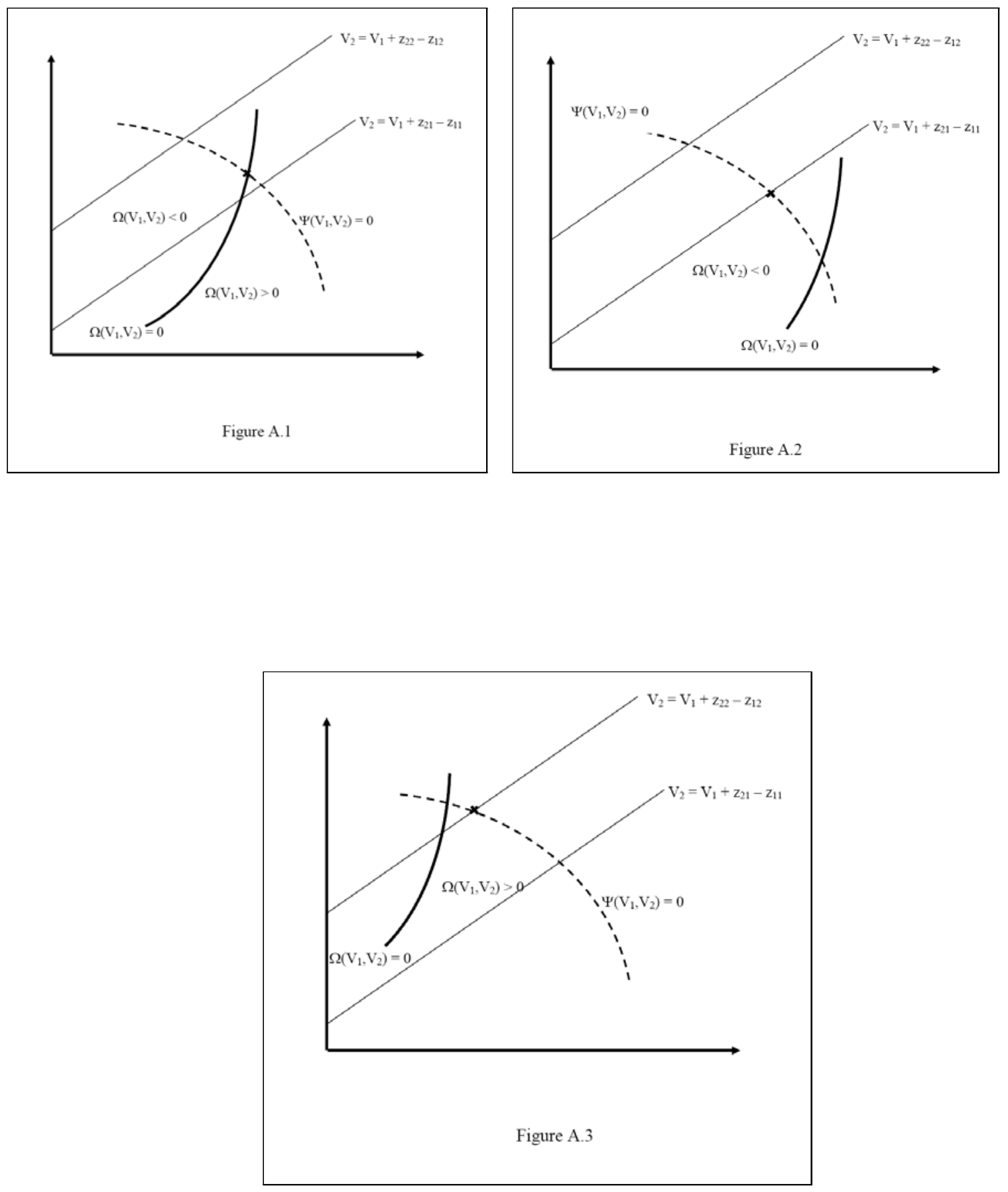